NISSUNA UMANA INVESTIGAZIONE SI PUO DIMANDARE VERA SCIENZIA S'ESSA NON PASSA PER LE MATEMATICHE DIMOSTRAZIONI LEONARDO DA VINCI

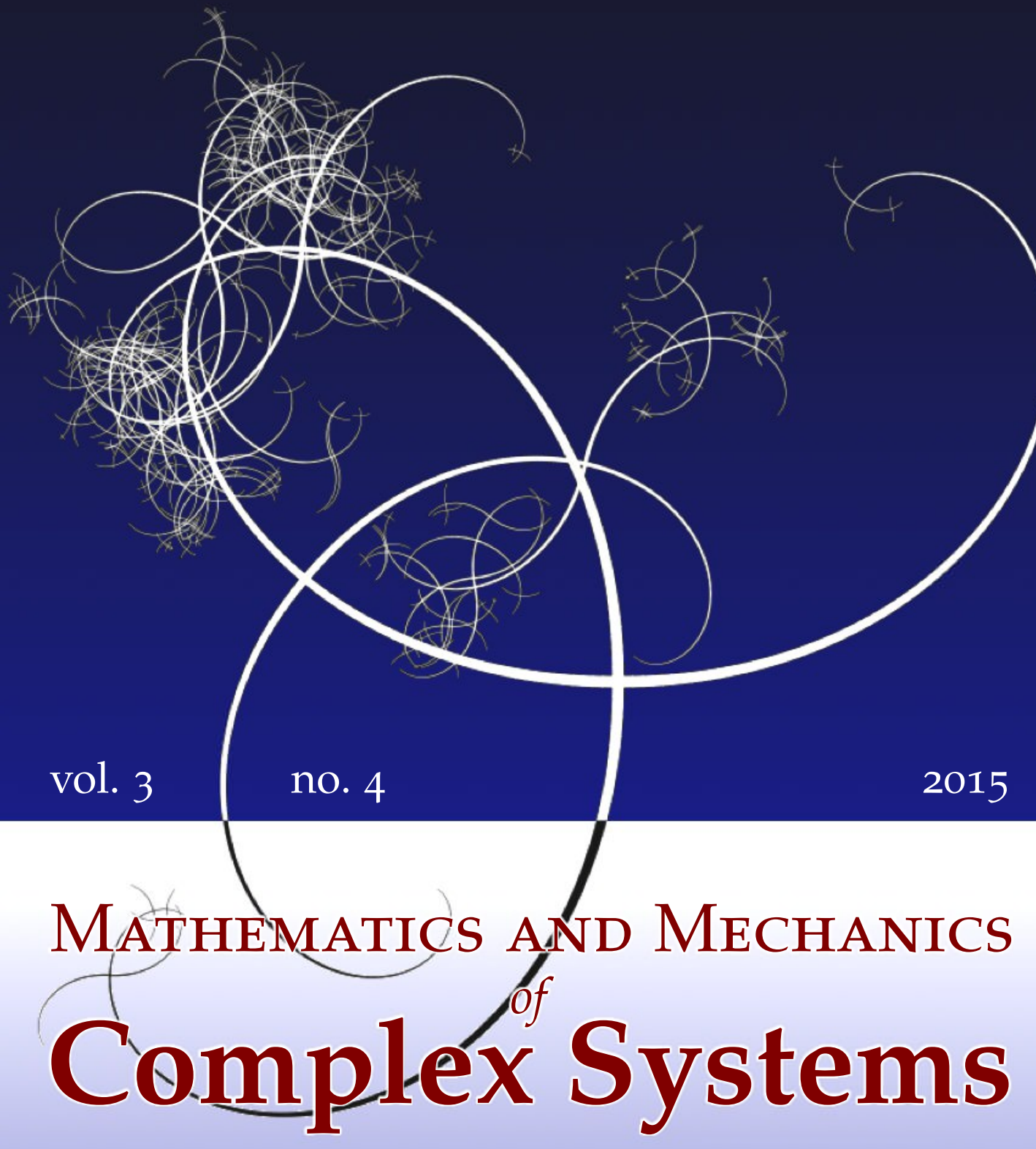

CHRISTIAN MARX

AN ANALYSIS OF THE LATITUDINAL DATA OF ERATOSTHENES AND HIPPARCHUS 


\title{
AN ANALYSIS OF THE LATITUDINAL DATA OF ERATOSTHENES AND HIPPARCHUS
}

\author{
CHRISTIAN MARX
}

\begin{abstract}
The extant data on latitudes ascribed to Eratosthenes and Hipparchus have been compiled and tested for consistency using adjustment theory. For the detected inconsistencies new explanations are given concerning the origin of the data. Several inconsistent data can be ascribed to Strabo. Differences in Hipparchus' data can often be explained by the different types and precision of the data. Gross errors in Eratosthenes' data are explained by their origin in lengths of sea routes. From Eratosthenes' data concerning Thule a numerical value for Eratosthenes' obliquity of the ecliptic is deduced.
\end{abstract}

\section{Introduction}

A precise specification of positions on the earth surface became possible in ancient geography by the introduction of reference systems and physical quantities for the description of positions. Eratosthenes (ca. 276-194 BC), founder of mathematical geography, introduced a grid of non-equidistant parallels and meridians for the positions of selected places. In his Geography he described the inhabited world using distance data and expressed his latitudinal data probably using meridian arc lengths. The astronomer and mathematician Hipparchus (ca. 190-120 BC) probably introduced the division of the full circle into $360^{\circ}$ into Greek astronomy and geography (e.g., [Dicks 1960, p. 149]). He transferred the concept of ecliptical longitude and latitude for the specification of star positions to the terrestrial sphere. Hipparchus' essential geographical work is his treatise Against the 'Geography' of Eratosthenes, wherein he discussed the works of Eratosthenes and gave a compilation of latitudes and equivalent astronomical quantities for several locations. Later Ptolemy (ca. 100-170 AD) used Hipparchus' concept and introduced a geographical coordinate system for his position data in his Geography (Geographike Hyphegesis, GH), which differs from today's system only by its zero meridian.

\section{Communicated by Lucio Russo.}

MSC2010: 01A20.

Keywords: Eratosthenes, Hipparchus, Strabo, latitudes, obliquity of the ecliptic, length of the longest day, prime meridian, Thule. 
The mentioned works of Eratosthenes and Hipparchus have been handed down only in fragments, mainly in Strabo's (ca. 63 BC - 23 AD) Geography (G; see [Jones 1917-1932; Radt 2002-2011]). The geographical fragments of Eratosthenes were compiled and commented on in [Berger 1880; Roller 2010], and those of Hipparchus in [Berger 1869; Dicks 1960]. In particular, the latitudinal data in the fragments are given partly redundantly and with differing numerical values. It is uncertain whether all the data originate with Eratosthenes or Hipparchus (see also [Roller 2010, p. 36]). Therefore, an investigation of their consistency is indicated. The aim of this contribution is to carry out such an investigation jointly for all the data under consideration, to ensure that all relations between the data are integrated. For this purpose, the data are grouped into systems of equations; when solving these systems appropriately, the inconsistencies of the data become evident (Sections 2 and 3). New explanations are given for the inconsistencies. The actual accuracy of the investigated ancient data is not the subject of this contribution. Some grossly erroneous data of Eratosthenes, however, are explained by their origin in the lengths of sea routes (Section 2.3).

Among Eratosthenes' latitudinal data there is a distance concerning Thule, the place visited by the geographer and astronomer Pytheas during his expedition to Great Britain in about 330 BC. From Eratosthenes' and Pytheas' information concerning Thule a numerical value for Eratosthenes' obliquity of the ecliptic is deduced (Section 2.4). A location for Thule based on new considerations of Pytheas' sea route and of the lengths of the nights in Thule is to be found in the Appendix.

\section{Eratosthenes' latitudinal data}

The latitudinal data of Eratosthenes considered in the following are based on the fragments given in [Roller 2010] (the following translations are taken from there). The investigations are limited to the locations in the western Oikoumene (the inhabited world known to the Greeks and Romans), in particular those in connection with Eratosthenes' prime meridian through Rhodes, because only these data are partly redundant. The data considered originate from Strabo's Geography, Pliny's Natural History (NH; see [Bostock and Riley 1855]) and Cleomedes' Caelestia (C). Figure 1 shows some of the locations.

Strabo and possibly Eratosthenes expressed latitudes and latitudinal differences by means of meridian arc lengths ( $b$ hereinafter and $b_{0}$ if with respect to the equator) in stadia (st). Eratosthenes introduced the value

$$
C=252,000 \mathrm{st}
$$

for the circumference of the earth (e.g., G II.5.7), so that for an arc of meridian

$$
1^{\circ} \widehat{=} C / 360=700 \text { st. }
$$




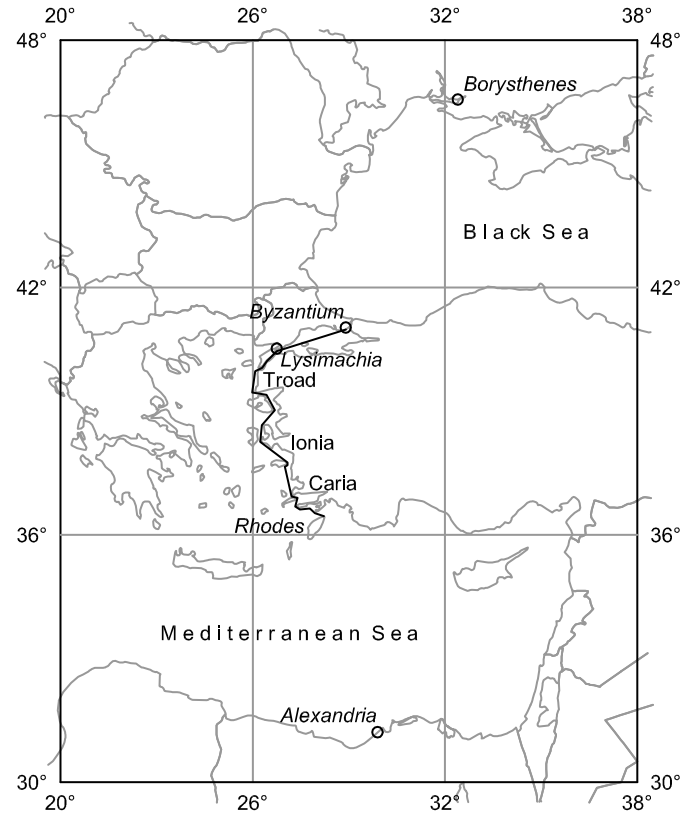

Figure 1. Places located on or near Eratosthenes' prime meridian (italics) and possible sea routes underlying Eratosthenes' data (thick line).

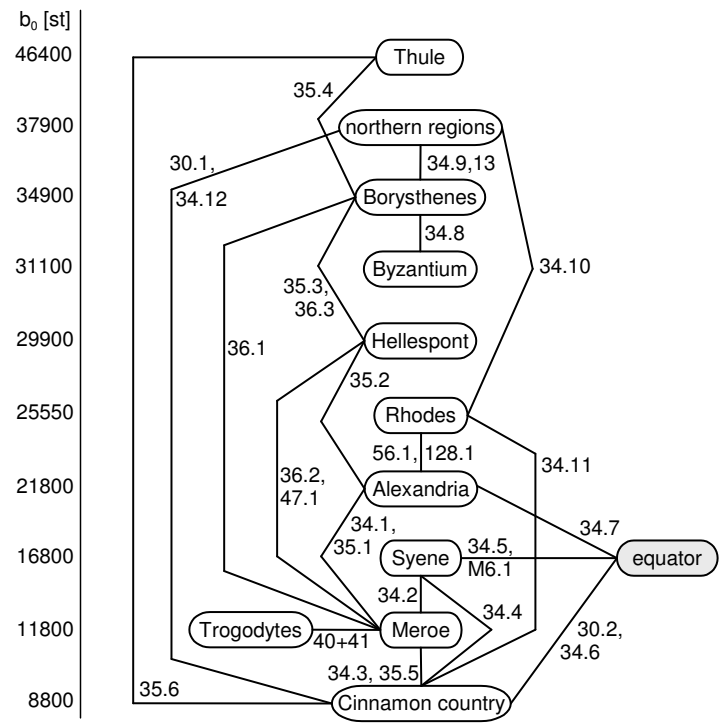

Figure 2. Graph of the latitude data of the western Oikoumene ascribed to Eratosthenes; the vertical order of the locations gives the meridian arc length $b_{0}$ from the equator (not to scale). 
Information presumably originating from Eratosthenes and the corresponding fragments $(\mathrm{F})$ and sources are given in Table 1. The F-numbers correspond to [Roller 2010]. Data occurring repeatedly within one fragment are listed and used once only. In addition, consecutive numbers have been introduced, separated from the F-number by a dot. If it follows from the textual source that two locations have the same latitude, $b$ is set to 0 . Figure 2 on the previous page shows a graph for Eratosthenes' data: an edge appears between two locations if at least one $b$ exists for them.

\begin{tabular}{|c|c|c|c|c|}
\hline $\mathrm{F}$ & Source & From & To & $b[\mathrm{st}]$ \\
\hline $30.1,34.12$ & G II.5.6, II.5.9 & Cinnamon country & northern regions & $<30,000$ \\
\hline $30.2,34.6$ & G II.5.6, II.5.7 & equator & Cinnamon country & 8,800 \\
\hline $34.1,35.1$ & G II.5.7, I.4.2 & Meroë & Alexandria & $\begin{array}{l}\approx 10,000 \\
=10\end{array}$ \\
\hline 34.2 & G II.5.7 & Meroë & Syene & 5,000 \\
\hline 34.3 & G II.5.7 & Cinnamon country & Meroë & $\approx 3,000$ \\
\hline 34.4 & G II.5.7 & Cinnamon country & Syene & 8,000 \\
\hline $34.5^{*}, \mathrm{M} 6.1^{*}$ & G II.5.7, C I.7 & equator & Syene & 16,800 \\
\hline 34.7 & G II.5.7 & equator & Alexandria & 21,800 \\
\hline 34.8 & G II.5.8 & Byzantium & Borysthenes & $\approx 3,800$ \\
\hline 34.9 & G II.5.9 & Borysthenes & northern regions & 4,000 \\
\hline 34.10 & G II.5.9 & Rhodes & northern regions & 12,700 \\
\hline 34.11 & G II.5.9 & Cinnamon country & Rhodes & 16,600 \\
\hline 34.13 & G II.5.8 & Borysthenes & northern regions & 3,000 \\
\hline 35.2 & G I.4.2 & Alexandria & Hellespont & $\approx 8,100$ \\
\hline $35.3,36.3$ & G I.4.2, II.5.42 & Hellespont & Borysthenes & 5,000 \\
\hline 35.4 & G I.4.2 & Borysthenes & Thule & $\approx 11,500$ \\
\hline 35.5 & G I.4.2 & $\begin{array}{l}\text { Cinnamon country, } \\
\text { Egyptian island, } \\
\text { Taprobane }\end{array}$ & Meroë & 3,400 \\
\hline 35.6 & G I.4.2 & Cinnamon country & Thule & 38,000 \\
\hline 36.1 & G II.5.42 & Meroë & Borysthenes & $\gtrsim 23,000$ \\
\hline $36.2,47.1$ & G II.5.42, G II.1.3 & Meroë & Hellespont & 18,000 \\
\hline $40+41^{*}$ & $\begin{array}{l}\text { G II.1.20, } \\
\text { NH II.185 }\end{array}$ & Meroë & $\begin{array}{r}\text { country of the } \\
\text { Trogodytes }\end{array}$ & 0 \\
\hline 56.1 & G II.1.33 & Alexandria & Rhodes & $\lesssim 4,000$ \\
\hline 128.1 & G II.5.24 & Alexandria & Rhodes & 3,750 \\
\hline
\end{tabular}

Table 1. Latitudinal data of the western Oikoumene derived from the fragments (F; with the exception of F34.13 from [Roller 2010]) ascribed to Eratosthenes; ${ }^{*}=$ see note in Section 2.1. The symbols $\lesssim$ and $\gtrsim$ stand for "somewhat smaller" and "somewhat larger". 
2.1. Notes on the data. At the southern limit of the inhabited world lies the Cinnamon country (F34/G II.5.7). For the northern limit, Eratosthenes gives two locations of differing latitudes: the "northern regions" (F34/G II.5.9) and Thule (F35/G I.4.2).

The Cinnamon country corresponds to the southern coast of the Gulf of Aden (cf. [Dicks 1960, p. 170]). The information in F30.1, F30.2 (G II.5.6) and F34.11 (G II.5.7) does not refer directly to the Cinnamon country but to the southern limit of the inhabited world. Their identicalness results from G II.5.7.

The data on the Borysthenes, the Dnieper River, ${ }^{1}$ refer to its mouth into the Black Sea.

The latitude of the Hellespont (Dardanelles) presumably corresponds to that of Eratosthenes' parallel through Lysimachia (near Bolayır, Gallipoli peninsula), which is mentioned in G II.5.40 (likewise [Berger 1880, p. 155]).

F34 (G II.5.7): Strabo says that $b_{0}$ of the tropic of Cancer corresponds to $\frac{4}{60}$ of $C$ (i.e. $C / 15=16,800 \mathrm{st}$ ), that the tropic goes through Syene and that $b_{0}$ of Syene is 16,800 st. The latter is applied here (F34.5). Eratosthenes uses $\frac{1}{15}$ of the full circle for the obliquity of the ecliptic $\varepsilon$ in this case, i.e.,

$$
\varepsilon_{\mathrm{r}}=24^{\circ},
$$

which was a common value in early Greek geography (cf. [Neugebauer 1975, pp. 733-734]).

F34.13 (G II.5.8): This fragment is introduced in addition to [Roller 2010] (see Section 2.2) but not used in the following test of consistency.

F36.1, F36.2 (G II.5.42), F47.1 (G II.1.3): In G II.5.42 Strabo deals with Hipparchus' data on the regions in the neighborhood of the Borysthenes and the southern parts of Lake Maeotis (Sea of Azov) and he states: "Eratosthenes says that these regions are a little more than 23,000 stadia [F36.1] from Meroë, since it is 18,000 stadia [F36.2] to the Hellespont and then 5,000 [F36.3] to Borysthenes." Roller [2010, p. 155] derives from this that the "...mouth of the Borysthenes is somewhat over 23,000 stadia from Meroë." From the text, however, it follows that $b$ for Meroë - Borysthenes is $(18,000+5,000) \mathrm{st}=23,000$ st. Thus, the text suggests that Eratosthenes differentiated between the latitude of the mouth of the Borysthenes and the latitude of the mentioned regions, which are situated further north than the mouth. ${ }^{2}$ Another interpretation results from F34.1/35.1 (Meroë - Alexandria) and F35.2 (Alexandria - Hellespont), which yield $b=18,100$ st for Meroë - Hellespont

\footnotetext{
${ }^{1}$ In antiquity, there was disagreement on the location of the Borysthenes; cf. Pliny, NH IV.83. For instance, Ptolemy (GH III.5) probably confuses the Borysthenes with the Hypanis and locates the Borysthenes at the Southern Bug (cf. [Marx and Kleineberg 2012, pp. 50, 53]).

${ }^{2}$ In fact, however, the southern parts of Lake Maeotis are further south than the Borysthenes.
} 
so that $b$ of Meroë - Borysthenes is 23,100 st. Possibly, Eratosthenes specified $b=23,100$ st for the mouth of the Borysthenes and its neighboring regions and Strabo described this value as "a little more than 23,000 st" and erroneously used 18,000 st instead of 18,100 st in his statement. Moreover, in G II.1.3 Strabo states: "From Meroë to the Hellespont is no more than 18,000 stadia [F47.1] ...".3 Since, however, he compares this value with the distance from India to the Bactrians, it is certainly only a rough value. Owing to the differences in the information, the values 23,000 st and 18,000 st are not used in the subsequent calculational test of consistency.

F40 (G II.1.20), F41 (NH II.185): According to F40, Eratosthenes agrees closely with Philo (a Ptolemaic officer; see [Roller 2010, p. 157]) that in Meroë the sun is at the zenith 45 days before the summer solstice. In order to test this, the dates of the year have been determined for 350-250 BC when the sun's altitude $a$ was maximal in Meroë $\left(\phi=16^{\circ} 56^{\prime}\right) \cdot{ }^{4}$ As a result, the sun reached its maximal $a \approx 90^{\circ}$ either 45 or 46 days before and 46 or 45 days after the day of the summer solstice. Hence, the information of F40 is probably based on an accurate observation. Eratosthenes' $b$-data yield $b_{0}=11,800$ st for Meroë (see Section 2.2), which corresponds to $\phi=16^{\circ} 51^{\prime}$, in good agreement with the actual $\phi$. According to F41, the shadows fall to the south 45 days before and after the summer solstice in the country of the Trogodytes. That corresponds to the information of F40 on Meroë. It is not known whether Eratosthenes derived latitudes from the information in F40 and F41. At least, however, it can be assumed that Eratosthenes believed the Trogodytes and Meroë to be located on the same latitude. Thus, $b=0$ is introduced here for Meroë - Trogodytes only.

F128.1 (G II.5.24): The distance Alexandria - Rhodes is not explicitly indicated as a difference in latitudes, but it was found by "... using the shadow of a gnomon ...", so it is considered to be a $b$ value.

FM6 (C I.7): This fragment originates from Eratosthenes' work On the measurement of the Earth; see [Roller 2010, pp. 263-267]. According to this, Syene is located on the tropic of Cancer; thus, following F34, $b_{0}=16800$ st is applied here.

\footnotetext{
${ }^{3}$ I thank one of the referees for his reference to this text passage.

${ }^{4}$ The time of the summer solstice can be determined according to [Meeus 1991, pp. 165-167]. For a location of longitude $\lambda$ and latitude $\phi$ and for a given time $t$, the sun's altitude $a$ can be determined by the following calculation steps (for formulas see [Meeus 1991, pp. 84, 88-89, 135, 151-3]): obliquity of the ecliptic: $\varepsilon(t)$; mean anomaly of the sun: $M(t)$; mean ecliptic longitude of the sun: $L_{0}(t)$; equation of center: $C(t, M)$; true ecliptic longitude: $\Theta\left(L_{0}, C\right)$; right ascension of the sun: $\alpha(\Theta, \varepsilon)$; declination of the sun: $\delta(\Theta, \varepsilon)$; GMST: $\theta_{0}(t)$; hour angle: $H\left(\lambda, \alpha, \theta_{0}\right) ; a(\phi, \delta, H)$. (The software-implemented calculation was tested by comparison with the results of the online calculator of Cornwall et al. [2013].)
} 
2.2. Test of consistency. A consistency test is carried out simultaneously for all the data attributed to Eratosthenes by forming a system of equations representing the relations among them. For each given latitudinal datum $b_{i}^{j, k}$, the equation $b_{i}^{j, k}=b_{0}^{k}-b_{0}^{j}$ is introduced, where $b_{i}^{j, k}$ is the $i$-th given meridian arc length between the parallels of the $j$-th and $k$-th location and $b_{0}^{j}$ and $b_{0}^{k}$ are the meridian arc lengths between these locations and the equator. The latter are the unknowns of the system; they refer to the 11 locations in Figure 2 . When $j$ refers to the equator, $b_{0}^{j}$ is not an unknown but has the value 0 . When a $b_{i}^{j, k}$ is specified by an inequality $b>x$ or $b<x$, it is replaced by $b=x$ for the computation.

Since there are redundant and mutually inconsistent data, a numerical solution of the system is not directly possible. In order to achieve a consistent system of equations, an unknown correction $v_{i}$ (residual) is introduced for each datum $b_{i}^{j, k}$ :

$$
b_{i}^{j, k}+v_{i}=b_{0}^{k}-b_{0}^{j}, \quad i=1 \ldots n
$$

(where $n$ is the number of data), as usual in adjustment theory. The system (4) can be solved by minimizing an object function $S$ of the corrections $v_{i}$. In the present case the object function

$$
S=\sum_{i=1}^{n}\left|v_{i}\right| \rightarrow \min
$$

of the $L_{1}$-norm adjustment is appropriate because it is a resistant estimation method and therefore able to reveal inconsistencies of the data (see, e.g., [Marx 2013]; data errors are manifested in large values of the $v_{i}$ ). For the $b$ values which occur multiple times in Table 1, multiple equations are introduced so their influence is increased in the adjustment. The $L_{1}$-norm adjustment is numerically solved here by the simplex algorithm of [Barrodale and Roberts 1974] (BR-algorithm).

The imprecise data of F30.1, F34.12 and F56.1 expressed by inequalities are not included in the adjustment but also obtain corrections $v_{i}$ based on the determined unknowns. There remain $n=22$ data for the adjustment. The solution of the BR-algorithm yields $18 v_{i}$ being 0 ; the associated $b$-data are therefore consistent among each other. The remaining $v_{i} \neq 0$ are considered in the following. The analysis shows that the solutions for the $b_{0}$ can be regarded as to be in accord with Eratosthenes' original data, with the exception of the "northern regions" (see below). The $b_{0}$ are given in Figure 2 .

F30.1, F34.12; Cinnamon country - "northern regions"; $b<30,000 \mathrm{st} ; v=100 \mathrm{st}$ : the bound $b<30,000$ st is contradictory to $v>0$. If this is Eratosthenes' information, probably not all $b$-data of F34.3, F34.1/35.1, F35.2, F35.3/36.3 and F34.9 (Cinnamon country - Meroë - Alexandria - Hellespont - Borysthenes - "northern regions") originate from Eratosthenes, because they yield 30,100 st. One explanation is that $b=4,000$ st for Borysthenes - "northern regions" (F34.9/G II.5.9) is not 
from Eratosthenes but from Strabo. This $b$ value is already given in the preceding section, G II.5.8: "For, so far as science is concerned, it is sufficient to assume that, just as it was appropriate in the case of the southern regions to fix a limit of the habitable world by proceeding three thousand stadia south of Meroë [...], so in this case too we must reckon not more than three thousand stadia [F34.13] north of Britain [equivalently, Borysthenes: their latitudes are the same according to G II.5.8], or only a little more, say, four thousand stadia" [Jones 1917-1932, p. 445]. The text suggests that the value of 3,000 st (F34.13) may originate with Eratosthenes and the 4,000 st may be an alteration by Strabo. The value of 3,000 st yields an extent of the inhabited world of 29,000 st, which fulfills the condition $b<30,000$ st of F30.1 and F34.12, and the $b_{0}$ of the "northern regions" is 37,900 st. F34.10; Rhodes - "northern regions"; $b=12,700 \mathrm{st} ; v=650 \mathrm{st}: b$ is contradictory to the value 13,350 st, which follows from F128.1 (Alexandria - Rhodes) and F35.2, F35.3/36.3, F34.9 (Alexandria - Hellespont - Borysthenes - "northern regions"). Possibly, $b=12,700$ st originates from Strabo. 12,700 st minus 4,000 st for the part Borysthenes - "northern regions" (F34.9) yields 8700 st for the part Rhodes Borysthenes, but F128.1, F35.2 and F35.3/36.3 yield 9,350 st. The value 8,700 st, however, nearly corresponds to Hipparchus' value 8,600 st (cf. G II.1.12, II.5.41) so that Strabo possibly chose it following Hipparchus and used it for $b$ of F34.10.

F34.11; Cinnamon country - Rhodes; $b=16,600 \mathrm{st} ; v=150 \mathrm{st}$ : $b$ is contradictory to the sum 16,750 st of F34.3, F34.1/35.1, F128.1 (Cinnamon country - Meroë Alexandria - Rhodes). Possibly, $b=16,600$ st is Strabo's sum, which is not based on 3,750 st for the part Alexandria - Rhodes (F128.1) but on the 3,600 st given by Hipparchus (cf. G II.5.39 and Section 3.2).

F35.5; Cinnamon country - Meroë; $b=3,400 \mathrm{st} ; v=-400 \mathrm{st}: b$ is contradictory to $b=3,000$ st of F34.3, which equals Hipparchus' $b$ in G II.5.35. Strabo says in F35: " . . if we add 3,400 [F35.5] more beyond Meroë, so that we include the Egyptian island, the Kinnamomophoroi [Cinnamon country], and Taprobane, we have 38,000 stadia [F35.6]." Hence, the reason for an alteration of $b$ by Strabo could be the extent of the Egyptian island and/or of Taprobane. In F53 (G II.5.14) Strabo states that the Cinnamon country, Taprobane and the Island of the Egyptians are situated on the same parallel, but in view of the spatial extent of these three locations this can only be an approximate piece of information (e.g., Eratosthenes' estimate of the latitudinal extent of Taprobane is 7,000 st according to F76/NH VI.81). Strabo possibly introduced 3,400 st in order to obtain the round value of 38,000 st (F35.6) for the latitudinal extent of the inhabited world from its southern limit to Thule.

F35.6; Cinnamon country - Thule; $b=38,000 \mathrm{st} ; v=-400 \mathrm{st}: b$ equals the sum of the other $b$-data of F35 but it is 400 st too large with regard to the sum based on Eratosthenes' presumable $b=3,000$ st (F34.3) for Cinnamon country - Meroë; 
see F35.5. Thus, $b=38,000$ st is probably only a round sum for the extent of the inhabited world given by Strabo.

F36.1; Meroë - Borysthenes; $b \gtrsim 23,000$ st; $v=100$ st: Since the information on $b$ is consistent with $v>0$ and the small $v, \mathrm{~F} 36.1$ can be regarded as consistent.

F36.2, F47.1; Meroë - Hellespont; $b=18,000 \mathrm{st} ; v=100 \mathrm{st}: b$ is contradictory to the sum $b=18,100$ st of F34.1/35.1 and F35.2 (Meroë - Alexandria - Hellespont). Strabo ascribes F35.1 and F35.2 explicitly to Eratosthenes. The value 18,000 st possibly originates from Strabo; see Section 2.1.

F56.1; Alexandria - Rhodes; $b \lesssim 4,000 \mathrm{st} ; v=-250$ st: The information on $b$ is in accord with $v<0$ and $v$ is acceptable because 4,000 st is probably a roughly rounded value; hence, F56.1 can be considered to be consistent.

2.3. Sea routes in Eratosthenes' latitudinal data. The two southernmost $b$ of Cinnamon country - Meroë (F34.3/35.5) and of Meroë - Alexandria (F35.1) are (almost) correct. The values $b=3,000$ st of F34.3 and $b=3,400$ st of F35.5 correspond via (2) to $4^{\circ} 17^{\prime}$ and $4^{\circ} 51^{\prime}$, respectively; the actually value is $4^{\circ} 43^{\prime}$ (based on a central latitude of $12^{\circ} 13^{\prime}$ for the Cinnamon country). The $b$ value of F35.1 agrees with the actual $14^{\circ} 17^{\prime}$.

In contrast, the subsequent latitudinal differences Alexandria - Hellespont of F35.2 and Hellespont - Borysthenes of F35.3/36.3 show large errors. The $b=$ 8,100 st of $\mathrm{F} 35.2$ is $11^{\circ} 34^{\prime}$ and actually $9^{\circ} 23^{\prime}$; the error is $2^{\circ} 11^{\prime} \widehat{=} 1,528$ st. The $b=5,000$ st of $\mathrm{F} 35.3 / 36.3$ is $7^{\circ} 09^{\prime}$ and actually $6^{\circ} 01^{\prime}$; the error is $1^{\circ} 08^{\prime} \widehat{=} 793$ st.

Both erroneous latitudinal differences are explicable by Eratosthenes' conception that the prime meridian through Rhodes also runs through Meroë, Alexandria, Caria, Byzantium and (the mouth of) the Borysthenes (cf. G I.4.1, II.1.12, II.1.40). Figure 1 shows the position of the locations concerned. Moreover, Strabo says that it is generally agreed that the sea route Alexandria - Borysthenes is a straight line (G II.5.7). Consequently, it is likely that the latitudinal differences Alexandria Hellespont and Hellespont - Borysthenes are based on the lengths of the sea routes, which were supposed to take course along the meridian (also assumed by Bunbury [1879, p. 640] and Roller [2010, p. 152]). This is considered in more detail below. The lengths of the sea routes could have been derived from journey times and estimates of the speed, which was a usual procedure according to GH I.9.4, I.17.6.

F35.2, Alexandria - Hellespont: At least for the Alexandria - Rhodes part it is known that Eratosthenes had information on the length of the sea route from navigators. For this part Eratosthenes gives his own $b=3,750$ st (F128.1) and additionally the two lengths 4,000 st and 5,000 st for the corresponding sea route based on the assumptions of navigators (F128/G II.5.24). The large difference between both lengths shows the large uncertainty of such information. If for the 
latitudinal difference Alexandria - Rhodes Eratosthenes' 3,750 st are used, then $(8,100-3,750) \mathrm{st}=4,350$ st remain for the rest of distance F35.2, i.e. for Rhodes - Hellespont. Figure 1 shows a possible sea route from Rhodes to Hellespont (Lysimachia). It has a length of ca. $650 \mathrm{~km}$. In order to convert this into stadia, use is made not of (2), which only applies to $b$, but of a conventional stadium length. The Egyptian stadium of $157.5 \mathrm{~m}$ (cf. [Dilke 1985, p. 33]) is chosen, ${ }^{5}$ which yields $650 \mathrm{~km}=4,127 \mathrm{st}$, in good agreement with the ancient value of 4,350 st.

F35.3/36.3, Hellespont - Borysthenes: $b$ of the part Byzantium - Borysthenes is 3,800 st according to F34.8 (G II.5.8; this value is ca. 100 st less than the actual value). For the rest of distance F35.3, i.e. for Hellespont - Byzantium, 1,200 st remain $(5,000-3,800)$. The assumed sea route Hellespont - Byzantium shown in Figure 1 has a length of $195 \mathrm{~km}=1,238 \mathrm{st}$, in good agreement with the ancient value of 1,200 st.

2.4. Eratosthenes' obliquity of the ecliptic. Strabo states (F34/G II.5.8) that, according to Pytheas, in Thule the arctic circle coincidences with the tropic of Cancer. The arctic circle delimits the region of the circumpolar stars in the sky, which do not set (see, e.g., [Dicks 1960, p. 165]). Thus, its declination is

$$
\delta_{\mathrm{a}}=90^{\circ}-\phi,
$$

where $\phi$ is the latitude of the observer. Strabo's information means that $\delta_{\mathrm{a}}$ equals the obliquity of the ecliptic $\varepsilon$. Hence, for Thule $\phi=90^{\circ}-\varepsilon$; in other words, Thule is on the northern polar circle. There the sun does not set at the summer solstice, which corresponds to Pliny's information (NH IV.30) that at the summer solstice there are no nights in Thule. The value of $\varepsilon$ was $23^{\circ} 44^{\prime}$ at the time of Pytheas' voyage ${ }^{6}{ }^{6}$ so the northern polar circle was at $\phi=66^{\circ} 16^{\prime}$. At Eratosthenes' time $\varepsilon$ was $23^{\circ} 43^{\prime}$, so $\phi=66^{\circ} 17^{\prime}$.

The computation of Section 2.2 yields $b_{0}=46,400$ st for Thule. This result is composed of the following $b$-data:

1. equator - Cinnamon Country: 8,800 st (F30.2, F34.6);

2. Cinnamon Country - Meroë: 3,000 st (F34.3, the value occurs twice in F34);

3. Meroë - Alexandria: 10,000 st (F34.1, F35.1);

4. Alexandria - Hellespont: 8,100 st (F35.2);

5. Hellespont - Borysthenes: 5,000 st (F35.3, F36.3);

6. Borysthenes - Thule: 11,500 st (F35.4).

The 2 nd $b$ value equals the difference between F34.4 (Cinnamon country - Syene)

\footnotetext{
${ }^{5}$ Some evidence for the Egyptian stadium is provided by the investigation of Ptolemy's longitudes in [Russo 2013] for example.

${ }^{6}$ Computed according to [Meeus 1991, p. 135].
} 
and F34.2 (Meroë - Syene). The sum of 13,000 st of the 2nd and 3rd $b$ values (Cinnamon country - Alexandria) equals the difference between F34.7 (Alexandria) and the 1 st $b$ value. The sum of the 3rd, 4th and 5th $b$ values (Meroë Borysthenes) amounts to 23,100 st and is confirmed by F36.1, where $\gtrsim 23,000$ st is given. Hence, considering the $3 \mathrm{rd}$ and 5 th $b$ value to be correct, also the 4th $b$ value is confirmed. The 6 th $b$ value was probably calculated from the $b_{0}$ values of Thule and the Borysthenes.

Eratosthenes' $b_{0}$ for Thule corresponds to

$$
46,400 \text { st } \approx 66^{\circ} 17^{\prime}
$$

which equals the actual position of the polar circle at Eratosthenes' time. Apparently, he had a good knowledge of the value of $\varepsilon$, which he used in conjunction with Pytheas' information for the location of Thule. Assuming for $b_{0}=46,400 \mathrm{st}$ a resolution of 100 st, the limits for $\varepsilon$ are:

$$
\begin{aligned}
90^{\circ}-(46,450 / 700)^{\circ} & <\varepsilon<90^{\circ}-(46,350 / 700)^{\circ} \\
23^{\circ} 39^{\prime} & \leq \varepsilon \leq 23^{\circ} 47^{\prime} .
\end{aligned}
$$

Ptolemy states in his Mathematike Syntaxis (MS; see [Manitius 1912; Toomer 1984]) I.12 that the ratio $t=\frac{11}{83}$ of the arc between the tropics to the full meridian equals nearly Eratosthenes' value, which was also used by Hipparchus. Ptolemy's $t$ leads to

$$
\varepsilon_{\mathrm{m}}=23^{\circ} 51^{\prime} 20^{\prime \prime} .^{7}
$$

Hipparchus presumably used

$$
\varepsilon_{\mathrm{h}}=23^{\circ} 40^{\prime}
$$

(cf. [Diller 1934]). Probably, this is Eratosthenes' value. It corresponds to $t \approx \frac{10.91}{83}$, which does not differ significantly from Ptolemy's value. For the polar circle, i.e. Thule, it yields $\phi=66^{\circ} 20^{\prime}$ and $b_{0}=46,433 \mathrm{st} \approx 46,400 \mathrm{st}$, in agreement with the value resulting from Eratosthenes' $b$-data. Possibly Eratosthenes specified $b$ of Borysthenes - Thule as "about" 11,500 st because it was calculated from $b_{0}=46,433$ of Thule and $b_{0}=34,900$ st of the Borysthenes so that 11,533 st was obtained. Or he considered the derived $b$ of Borysthenes - Thule to be unreliable because $b_{0}$ of the Borysthenes was based on the lengths of the sea routes reported by navigators (see Section 2.3).

From F34 (G II.5.7) can be derived that Eratosthenes' value for $\varepsilon$ was $\frac{4}{60}$ of $C$, or $24^{\circ}$. This value is not contradictory to $23^{\circ} 40^{\prime}$ because it is based on the division of the full circle into 60 parts. It was a common value for $\varepsilon$ in early Greek geography,

${ }^{7}$ Manitius [1912, vol. 1, p. 44, footnote b] wrongly infers from MS I.12 that $\varepsilon_{\mathrm{m}}$ was Eratosthenes' value. According to the text, however, this applies only approximately (see also [Jones 2011, p. 459]). 
and Eratosthenes probably gave this rough value as well as a more precise value in his works. Later ancient authors also mention or use this value, although a more accurate value was known (e.g. Ptolemy in GH VII.6.7; see [Neugebauer 1975, p. 734]). Strabo was probably not interested in Eratosthenes' more precise value, so he adopted the value $\frac{4}{60} C$ only. Similarly, in G II.5.43 Strabo refers the reader to Hipparchus' work concerning astronomical matters.

\section{Hipparchus' latitudinal data}

The investigations of Hipparchus' latitudinal data are mainly based on the fragments (F) given by Dicks [1960] (the following translations are taken from it). The data mainly originate from Hipparchus' treatise Against the 'Geography' of Eratosthenes, which consisted of three books (cf. [Dicks 1960, p. 37]). Latitudinal data occurred in the second book (F12-34) and the third (F35-63), the majority in the third book. The third book contained astronomical data for several latitudes. Strabo gives extracts of this compilation; for instance he limits the data to the inhabited world (cf. G II.5.34). The occurring types of latitudinal data are: meridian arc length $b$ or $b_{0}$ between the parallels of two locations or from the equator (in st); noon altitude $a$ of the sun at the winter solstice given in astronomical cubits (c; $1 \mathrm{c}=2^{\circ}$ ); ratio $r=g: s$ of the length $g$ of the gnomon to the length $s$ of its shadow; length $M$ of the longest day (summer solstice) in (equinoctial) hours. Presumably, the meridian arc lengths do not originate from Hipparchus but were calculated by Strabo from latitudes by means of (2) (e.g., [Berger 1869, p. 37]). The $M$-data are compared with their corresponding meridian arc lengths by Rawlins [2009]; for the sake of completeness, however, they are included in the following investigation.

With the exception of F15 (G II.1.12), the latitudinal data in the fragments of Hipparchus' second book (F19/G II.1.12, F22/G II.1.29, F24/G II.1.34, F26/G II.1.36) do not have connections to the data in Hipparchus' third book. The only data which positions the concerned locations absolutely in latitude is the imprecise information that $b$ of Athens - Babylon "... is not greater than 2,400 stades ..." (F22). Hipparchus gives this limit only in order to show that Eratosthenes' positioning of the Taurus is wrong. Furthermore, there are no connections among the data of the second book which would cause redundant relations among each other. Thus, these data are not included in the following investigations; for a discussion of the data see [Dicks 1960].

In places Strabo gives one latitudinal data which applies to several locations. Among these locations there may be additions by Strabo which do not originate from Hipparchus (see [Berger 1869, p. 41]). Owing to uncertainties in this regard, however, all locations are taken into account here. If within a fragment more than two locations are related by one data, the derivable relations are kept as compact 
as possible ${ }^{8}$. Data which occur repeatedly within one fragment are listed and used once only.

A further source is Hipparchus' Commentary on the Phenomena of Aratus and Eudoxus (CP; see [Manitius 1894]), which contains only a few latitudinal data. In the Commentary altitudes of the pole $a_{\mathrm{p}}$ are given, which equal the latitude $\phi$, as well as polar distances $\zeta_{\mathrm{a}}$ of the ever visible circle (the arctic circle) or of the never visible circle (which delimits the region of the stars which do not rise).

The data considered and their sources are compiled in Table 2. ${ }^{9}$ Fragment numbers 15-61 correspond to [Dicks 1960] and are extended by a consecutive number separated by a dot. F62-71 refer to the Commentary and are additionally introduced here (only partly mentioned by [Dicks 1960], [Berger 1869, p. 54, F V 11], [Shcheglov 2007]). Figure 3 shows the data in form of a graph.

For a comparison and a joint analysis of the consistency of the data, data not given as $b$ were converted into $b$. The conversions of the given quantities into $\phi$ are considered in the following; $\phi$ can be converted into $b_{0}$ by means of (2). If further parameters are included in a conversion, one must consider in choosing them whether the quantities to be compared were originally independently determined or not.

The conversion of $a$ into $\phi$ is

$$
\phi=90^{\circ}-a+\delta,
$$

where $\delta$ is the sun's declination. ${ }^{10}$ If one denotes by $a_{\mathrm{s}}$ and $a_{\mathrm{w}}$ the sun's altitudes on the summer and winter solstices, $\delta$ equals $\varepsilon$ and $-\varepsilon$ respectively (see Figure 4):

$$
\begin{aligned}
& \phi=90^{\circ}-a_{\mathrm{s}}+\varepsilon, \\
& \phi=90^{\circ}-a_{\mathrm{w}}-\varepsilon .
\end{aligned}
$$

Since an ancient conversion from $\phi$ to $a$ is assumed here, the value used for $\varepsilon$ is the $\varepsilon_{\mathrm{h}}$ of (10), which presumably underlies Hipparchus' conversion from $M$ to $\phi$ (see [Diller 1934]) and differs only slightly from the actual value of $23^{\circ} 43^{\prime}$ in Hipparchus' time.

\footnotetext{
${ }^{8}$ In the case of information such as "A, B, C are $x$ st distant from D, E, F", not all nine derivable distances from A, B, C to D, E, F are introduced but only the following five distances: A - D: $b=x$ st; $\mathrm{A}-\mathrm{B}, \mathrm{A}-\mathrm{C}, \mathrm{D}-\mathrm{E}, \mathrm{D}-\mathrm{F}: b=0$. This is advisable because the value $x$ was surely not determined for all nine distances.

${ }^{9}$ I thank one of the referees for the information that the value $b=12,500$ st in G II.1.18, given in [Neugebauer 1975, p. 1313] for Massalia - 19 h parallel, is not from Hipparchus but from Strabo.

${ }^{10}$ Neugebauer [1975, p. 304] states that the $a$-data form an arithmetic progression of the second order. This is based, among others, on the value $a=3 \mathrm{c}$ for $M=19 \mathrm{~h}$. In F61 (G II.1.18), however, Strabo says that the $a$ belonging to $M=19 \mathrm{~h}$ is less than $3 \mathrm{c}$. An arithmetic progression is not considered here.
} 


\begin{tabular}{|c|c|c|c|c|c|}
\hline $\mathrm{F}$ & Source & From & To & $b[\mathrm{st}]$ & Original \\
\hline 15.1 & G II.1.12 & Meroë & Byzantium & $\approx 18,000$ & \\
\hline 43.1 & G II.5.35 & Cinnamon c. & Meroë & 3,000 & \\
\hline $43.2,44.1$ & G II.5.35, II.1.13 & equator & Cinnamon c. & $\begin{array}{l}=8,800 \\
\approx\end{array}$ & \\
\hline 43.3 & G II.5.35 & Meroë & Syene & 5,000 & \\
\hline 46.1 & G II.5.36 & Meroë kl. & Ptolemais & 0 & \\
\hline 46.2 & G II.5.36 & equator & Meroë kl. & 11,600 & $M=13 \mathrm{~h}$ \\
\hline 46.3 & G II.5.36 & equator & Meroë kl. & 11,600 & see p. 325 \\
\hline 47.1 & G II.5.36 & Syene & Berenice & 0 & \\
\hline 47.2 & G II.5.36 & Syene & c. of Trogodytes & 0 & \\
\hline 47.3 & G II.5.36 & equator & Syene & 16,602 & see p. 326 \\
\hline 47.4 & G II.5.36 & equator & Syene & 16,800 & $M=13 \frac{1}{2} \mathrm{~h}$ \\
\hline 48.1 & G II.5.38 & Alexandria kl. & Alexandria & $\approx 400$ & \\
\hline 48.2 & G II.5.38 & Alexandria & Cyrene & 0 & \\
\hline 48.3 & G II.5.38 & equator & Alexandria kl. & 21,400 & $M=14 \mathrm{~h}$ \\
\hline 48.4 & G II.5.38 & equator & Alexandria kl. & 21,400 & see p. 326 \\
\hline 48.5 & G II.5.38 & Alexandria kl. & Carthage & 1,300 & \\
\hline 48.6 & G II.5.38 & equator & Carthage & 22,730 & $r_{\mathrm{e}}=\frac{11}{7}$ \\
\hline 49.1 & G II.5.35 & Ptolemais $^{\mathrm{Ph}}$ & Sidon/Tyre & 0 & \\
\hline 49.2 & G II.5.35 & equator & Ptolemais $^{\mathrm{Ph}}$ & 23,400 & $M=14 \frac{1}{4} \mathrm{~h}$ \\
\hline 49.3 & G II.5.35 & Alexandria & Ptolemais $^{\mathrm{Ph}}$ & $\approx 1,600$ & \\
\hline 49.4 & G II.5.35 & Carthage & Ptolemais $^{\mathrm{Ph}}$ & $\approx 700$ & \\
\hline 50.1 & G II.5.39 & Rhodes & Peloponnese & 0 & \\
\hline 50.2 & G II.5.39 & Rhodes & Xanthus & 0 & \\
\hline 50.3 & G II.5.39 & Rhodes & Syracuse & 400 & \\
\hline 50.4 & G II.5.39 & equator & Rhodes & 25,400 & $M=14 \frac{1}{2} \mathrm{~h}$ \\
\hline 50.5 & G II.5.39 & Alexandria & Rhodes & 3,640 & \\
\hline 51.1 & G II.5.40 & Alexandria $^{T r}$ & Amphipolis & 0 & \\
\hline 51.2 & G II.5.40 & Alexandria $^{T r}$ & Apollonia & 0 & \\
\hline 51.3 & G II.5.40 & Alexandria $^{\operatorname{Tr}}$ & s. Rome, n. Naples & 0 & \\
\hline 51.4 & G II.5.40 & equator & Alexandria $^{\mathrm{Tr}}$ & 28,800 & $M=15 \mathrm{~h}$ \\
\hline 51.5 & G II.5.40 & Alexandria & Alexandria $^{\operatorname{Tr}}$ & 7,000 & \\
\hline 51.6 & G II.5.40 & equator & Alexandria $^{\operatorname{Tr}}$ & $>28,800$ & \\
\hline 51.7 & G II.5.40 & Rhodes & Alexandria $^{\mathrm{Tr}}$ & 3,400 & \\
\hline 51.8 & G II.5.40 & Alexandria $^{\operatorname{Tr}}$ & Byzantium & 1,500 & \\
\hline 51.9 & G II.5.40 & Byzantium & Nicaea & 0 & \\
\hline $\begin{array}{r}51.10,53.2 \\
54.1,55.1\end{array}$ & $\begin{array}{l}\text { G II.5.40, I.4.4 } \\
1 \quad \text { II.5.8, II.1.12 }\end{array}$ & Byzantium & Massalia & 0 & \\
\hline
\end{tabular}

Table 2. Latitudinal data derived from the fragments (F; with the exception of F62.1-71.1 from [Dicks 1960]) ascribed to Hipparchus; $\mathrm{n} .=$ north of, $\mathrm{s} .=$ south of, $\mathrm{c} .=$ country, $\mathrm{kl} .=\mathrm{klima},{ }^{\mathrm{Tr}}=$ in the Troad (i.e. Dalyan), ${ }^{\mathrm{Ph}}=$ in Phoenicia (i.e. Acre). 


\begin{tabular}{|c|c|c|c|c|c|}
\hline $\mathrm{F}$ & Source & From & To & $b[\mathrm{st}]$ & Original \\
\hline 52.1 & G II.5.41 & equator & Byzantium & 30,300 & $M=15 \frac{1}{4} \mathrm{~h}$ \\
\hline 52.2 & G II.5.41 & equator & Byzantium & 30,243 & $r_{\mathrm{s}}=120 / 41 \frac{4}{5}$ \\
\hline 52.3 & G II.5.41 & Rhodes & Byzantium & $\approx 4,900$ & \\
\hline 52.4 & G II.5.41 & equator & Byzantium & $\approx 30,300$ & \\
\hline 53.1 & G I.4.4 & Borysthenes & Britain (?) & 0 & \\
\hline 56.1 & G II.5.41 & Byzantium & Mid-Pontus & $\approx 1,400$ & \\
\hline 56.2 & G II.5.41 & equator & Mid-Pontus & 31,700 & $M=15 \frac{1}{2} \mathrm{~h}$ \\
\hline 56.3 & G II.5.41 & equator & Mid-Pontus & 31,500 & see p. 331 \\
\hline 57.1 & G II.5.42 & Byzantium & Lk. Maeotis & $\approx 3,800$ & \\
\hline 57.2 & G II.5.42 & equator & Lk. Maeotis & 34,100 & $M=16 \mathrm{~h}$ \\
\hline 57.3 & G II.5.42 & equator & Lk. Maeotis & 34,100 & \\
\hline 57.4 & G II.5.42 & equator & Lk. Maeotis & 33,833 & $a_{\mathrm{w}}=9 \mathrm{c}$ \\
\hline $58.1,59.3$ & G II.1.18, II.1.12 & Borysthenes & Celtica & 0 & \\
\hline 58.2 & G II.1.18 & equator & Borysthenes & 33,833 & $a_{\mathrm{w}}=9 \mathrm{c}$ \\
\hline 59.1 & G II.1.12 & Byzantium & Borysthenes & 3,700 & \\
\hline 59.2 & G II.1.12 & Massalia & Borysthenes & 3,700 & \\
\hline 59.4 & G II.1.13 & equator & Borysthenes & 34,000 & \\
\hline 60.1 & G II.5.42 & Byzantium & n. Lk. Maeotis & 7,700 & $6,300 \mathrm{st}$ \\
\hline 60.2 & G II.5.42 & equator & n. Lk. Maeotis & 38,033 & $a_{\mathrm{w}}=6 \mathrm{c}$ \\
\hline 60.3 & G II.5.42 & equator & n. Lk. Maeotis & 38,000 & $M=17 \mathrm{~h}$ \\
\hline 61.1 & G II.1.18 & Massalia & Celtica & 7,700 & $6,300 \mathrm{st}$ \\
\hline 61.2 & G II.1.18 & equator & Celtica & 38,033 & $a_{\mathrm{w}}=6 \mathrm{c}$ \\
\hline 61.3 & G II.1.18 & Massalia & 18 h-region & 10,500 & $9,100 \mathrm{st}$ \\
\hline 61.4 & G II.1.18 & equator & 18 h-region & 40,833 & $a_{\mathrm{w}}=4 \mathrm{c}$ \\
\hline 61.5 & G II.1.18 & equator & inhabited region & $>42,233$ & $a_{\mathrm{w}}<3 \mathrm{c}$ \\
\hline 61.6 & G II.1.18 & equator & inhabited region & 42,800 & $M=19 \mathrm{~h}$ \\
\hline 61.7 & G II.1.18 & equator & 18 h-region & 40,800 & $M=18 \mathrm{~h}$ \\
\hline 62.1 & CP 1.3.6 & equator & Greece & 25,809 & $r_{\mathrm{e}}=\frac{4}{3}$ \\
\hline 62.2 & CP 1.3.6 & equator & Greece & 26,024 & $M=14 \frac{3}{5} \mathrm{~h}$ \\
\hline 62.3 & CP 1.3.6 & equator & Greece & $\approx 25,900$ & $a_{\mathrm{p}} \approx 37^{\circ}$ \\
\hline 63.1 & CP 1.3.7 & equator & Alexandria $^{\operatorname{Tr}}$ & 28,753 & $M=15 \mathrm{~h}$ \\
\hline 63.2 & CP 1.3 .7 & equator & Alexandria $^{\mathrm{Tr}}$ & $\approx 28,700$ & $a_{\mathrm{p}} \approx 41^{\circ}$ \\
\hline 64.1 & CP I.3.12 & equator & Athens & 26,024 & $M=14 \frac{3}{5} \mathrm{~h}$ \\
\hline 64.2 & CP I.3.12 & equator & Athens & $\approx 25,900$ & $a_{\mathrm{p}} \approx 37^{\circ}$ \\
\hline 65.1 & CP I.4.8 & equator & Athens & 25,809 & $r_{\mathrm{e}}=\frac{4}{3}$ \\
\hline $65.2,70.1$ & CP I.4.8, I.11.8 & equator & Athens & $\approx 25,900$ & $\zeta_{\mathrm{a}} \approx 37^{\circ}$ \\
\hline $\begin{array}{l}66.1,67.1, \\
\quad 71.1\end{array}$ & $\begin{array}{l}\text { CP I.7.11, I.7.14, } \\
\text { II.4.2 }\end{array}$ & equator & Greece & 25,308 & $M=14 \frac{1}{2} \mathrm{~h}$ \\
\hline 68.1 & CP I.7.21 & equator & Athens & 25,900 & $\zeta_{\mathrm{a}}=37^{\circ}$ \\
\hline 69.1 & CP I.11.2 & equator & Greece & 25,900 & $\zeta_{\mathrm{a}}=37^{\circ}$ \\
\hline 70.2 & CP I.11.8 & equator & Rhodes & 25,200 & $\zeta_{\mathrm{a}}=36^{\circ}$ \\
\hline
\end{tabular}

Table 2 (continued). 


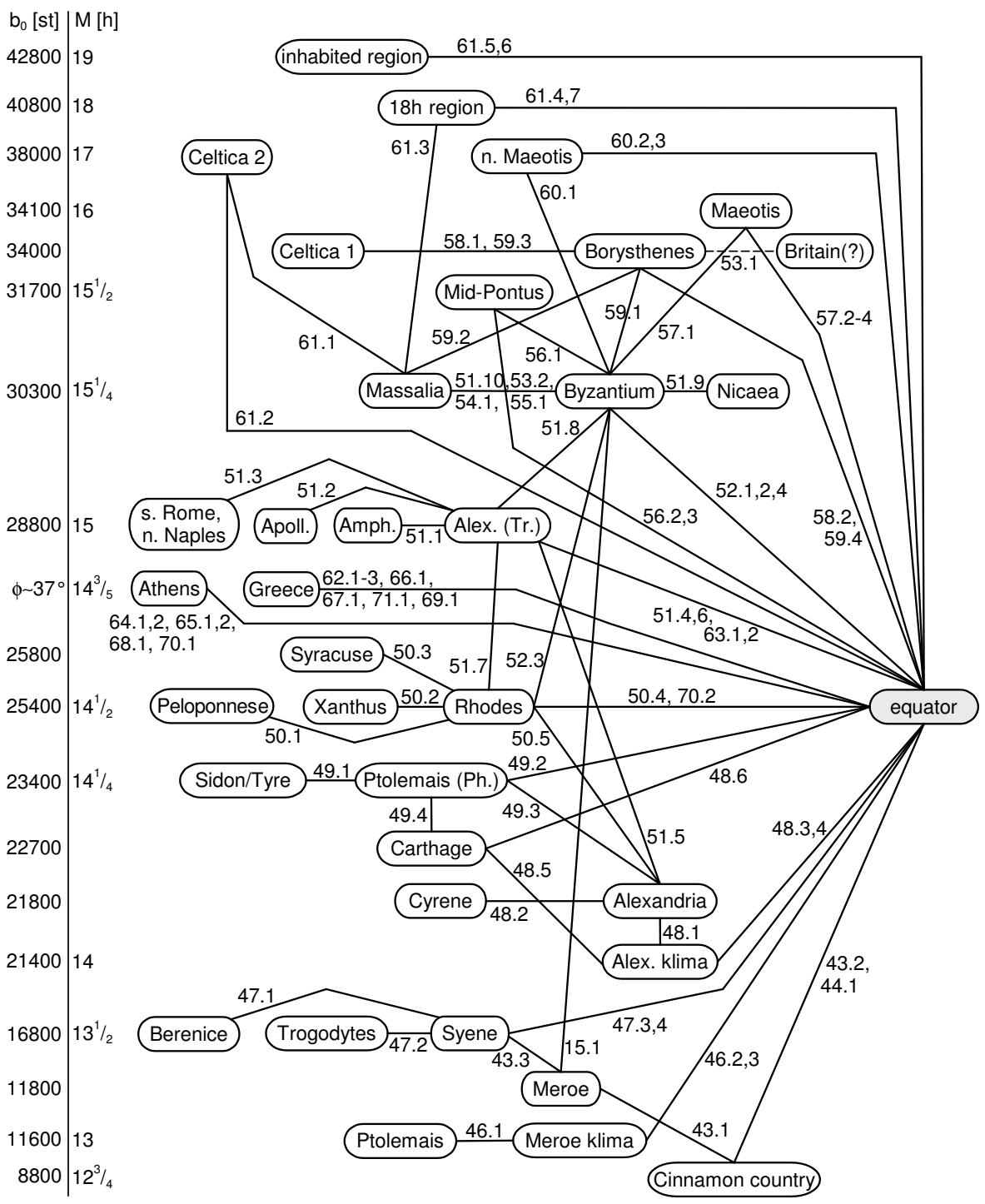

Figure 3. Graph of the latitudinal data ascribed to Hipparchus; the vertical order of the locations gives the meridian arc length $b_{0}$ from the equator (not to scale); s. = south of, n. = north of.

The ratio $r$ refers to the equinox or the summer solstice. In the case of the equinox, $\phi$ is computed from the ratio $r_{\mathrm{e}}$ by

$$
\phi=\arctan \left(1 / r_{\mathrm{e}}\right)
$$


Such an equinoctial ratio is not expected to be the result of a measurement, because at the equinox only unreliable gnomon measurements are possible, in contrast to the solstices (cf. [Rawlins 2009]). In the case of a ratio $r_{\mathrm{s}}$, referring to the summer solstice, a real measurement can be expected and it holds true that

$$
\phi=\arctan \left(1 / r_{\mathrm{s}}\right)+\varepsilon .
$$

To compare $r_{\mathrm{s}}$ with an independently determined meridian arc length, the actual value for $\varepsilon$ must be used. The value $\varepsilon=23^{\circ} 43^{\prime}$ of Hipparchus' time is used here. Moreover, since the shadow is generated by the upper edge of the sun and not by its center, $\phi\left(r_{\mathrm{s}}\right)$ must be enlarged by a systematic error of $16^{\prime}$, whereby the radius of the sun disc is taken into account (cf., e.g., [Dicks 1960, p. 178]).

Ptolemy gives the calculation of $\phi$ from $M$ and vice versa by means of spherical trigonometry in MS II.3. The comparison of Hipparchus' $M$-data with the associated $b_{0}$-data by [Diller 1934] and [Rawlins 2009] suggests that Hipparchus used a conversion $\phi_{\mathrm{t}}(M, \varepsilon)$ based on spherical trigonometry too. The modern formulation of Ptolemy's computation of $\phi$ from $M$ is

$$
\phi_{\mathrm{t}}(M, \varepsilon)=\arctan \left(-\cos \left(M / 2 \cdot 15^{\circ} / \mathrm{h}\right) / \tan \varepsilon\right)
$$

( $M$ in h), which is applied here. For $\varepsilon$ the value $\varepsilon_{\mathrm{h}}$ is used, which probably underlies Hipparchus' conversion between $M$ and $\phi$ (see [Diller 1934; Rawlins 2009]). Since Hipparchus presumably converted $M$ into $\phi$ and Strabo $\phi$ into $b_{0}$, a conversion according to [Rawlins 2009] is used here: $\phi_{\mathrm{t}}(M)$ is rounded to the nearest twelfth of a degree and $b_{0}\left(\phi_{\mathrm{t}}\right)$ to the nearest hundred stadia. The latter rounding is not applied to the data in the Commentary.

For the conversion of $\zeta_{\mathrm{a}}=90^{\circ}-\delta_{\mathrm{a}}$ into $\phi$, equation (6) applies so that $\phi=\zeta_{\mathrm{a}}$.

3.1. Notes on the data. Data on the Borysthenes refer to its mouth, as in Section 2.1. In F57 (G II.5.42), however, Strabo discusses "the regions in neighborhood of the Borysthenes and the southern parts of Lake Maeotis". These regions are distinguished from the Borysthenes and referred to as "Lake Maeotis" here.

F15 (G II.1.12): From this passage it follows that Meroë and the southern headlands of India have the same latitude. According to G II.1.20, however, Hipparchus objects to that in his second book (cf. [Berger 1869, pp. 42, 97]), so the information is not considered here.

F43 (G II.5.35): According to this passage, the Cinnamon country is situated “... very nearly half-way between the equator and the summer tropic ... ." Following [Berger 1869, p. 44], it is assumed here that this inaccurate localization is not from Hipparchus.

F46.3 (G II.5.36): Diller [1934] indicates that $b_{0}=11,800$ st of Meroë, which results from F43 (G II.5.35), is contradictory to $b_{0} \approx 11,600$ st resulting from the 
conversion of $M=13 \mathrm{~h}$ of the associated klima ${ }^{11}$ in F46 (G II.5.36). Rawlins [2009] points out the difference between the city of Meroë and the Meroë klima and gives $b_{0}$ for the klima. According to that, for $b_{0}^{\mathrm{Mk}}$ of the Meroë klima and $b_{0}^{\mathrm{Ak}}$ of the Alexandria klima follows from F46: $b_{0}^{\mathrm{Mk}}+\left(b_{0}^{\mathrm{Mk}}-1,800 \mathrm{st}\right)=b_{0}^{\mathrm{Ak}}$, $b_{0}^{\mathrm{Mk}}=\left(b_{0}^{\mathrm{Ak}}+1,800 \mathrm{st}\right) / 2$. By means of $b_{0}^{\mathrm{Ak}}=21,400$ st (see Section 3.2) it follows that $b_{0}^{\mathrm{Mk}}=11,600 \mathrm{st}$.

F47.3 (G II.5.36): "In Syene [...] the sun stands in the zenith at the summer solstice ..." Thus, $a_{\mathrm{s}}=90^{\circ}$ can be derived. From (12) follows $\phi=\varepsilon$, to which the actual value $23^{\circ} 43^{\prime}$ is applied, since a real observation is assumed at the root. Hence, $b_{0}=16,602$ st.

F48.4 (G II.5.38): Hipparchus distinguishes between Alexandria and the region 400 st south of it (the Alexandria klima; see F48.1), where $M$ is $14 \mathrm{~h}$ (F48.3). The $r_{\mathrm{e}}$ of Alexandria specified by Strabo (F48.4) is $\frac{5}{7}$ (cf. [Neugebauer 1975, p. 336; Rawlins 2009]), emended to $\frac{5}{3}$ in [Jones 1917-1932, p. 511; Dicks 1960, p. 95] because $r_{\mathrm{e}}=\frac{5}{7}$ yields a totally wrong $\phi$; but following Neugebauer, $\frac{5}{7}$ is assumed to represent the ratio $m / M$ of the length $m$ of the shortest day to the length $M$ of the longest day, which was a common way to specify of the latitude. From $m=$ $24 \mathrm{~h}-M$ follows $M=24 \mathrm{~h} /(m / M+1)=14 \mathrm{~h}$, which is used here. Thus, contrary to the text, this value does not refer to Alexandria proper but to the Alexandria klima (likewise [Rawlins 2009]).

F48.6 (G II.5.38): Strabo gives $r_{\mathrm{e}}=\frac{11}{7}$ for Carthage, which yields the grossly erroneous $\phi=32^{\circ} 28^{\prime}$ via (14) (actual $\phi=36^{\circ} 51^{\prime}$ ). Rawlins [1985; 2009] assumes a similar error for Carthage as for the Alexandria klima (see F48.4). According to this, the given $r_{\mathrm{e}}=\frac{11}{7}$ would be an $M / \mathrm{m}$ ratio, which corresponds to the common klima of $M=14 \frac{2}{3}$ h (cf. [Neugebauer 1975, p. 722]). This possible explanation is not followed here. First, the ratio $\frac{5}{7}$ for the Alexandria klima is assumed to be an $m / M$ ratio, but the ratio $\frac{11}{7}$ for Carthage would be an $M / m$ ratio, so a further inconsistency in the text would have to be assumed. Second, Ptolemy gives $\phi=32^{\circ} 40^{\prime}$ and $M=14 \frac{1}{5} \mathrm{~h}$ for Carthage (GH IV.3.7, VIII.14.5). Since Ptolemy's data originate from Hipparchus' data rather than from Strabo's, ${ }^{12}$ Hipparchus' $\phi$ must be about $32^{\circ} 40^{\prime}$, consistent with the value resulting from $r_{\mathrm{e}}$.

F52.2 (G II.5.41): In F52 the ratio $r_{\mathrm{s}}=120 / 41 \frac{4}{5}$ is given for Byzantium. According to F53 (G I.4.4) Hipparchus found the same ratio in Byzantium as Pytheas in Massalia. If $r_{\mathrm{s}}$ is Hipparchus' ratio for Byzantium, a real measurement by Hipparchus

${ }^{11}$ The term klima denoted a latitudinal strip or a latitude which was assigned to a specific $M$ value; in this regard see, e.g., [Honigmann 1929; Dicks 1960, pp. 154-164; Neugebauer 1975, pp. 725-727].

${ }^{12}$ For example, Ptolemy states (GH I.4.2) that he had available certain altitudes of the pole due to Hipparchus. 
is unlikely because the ratio yields an error of about $2^{\circ}$ with respect to the actual $\phi$. Jones [2002], for example, assumes a calculative origin for $r_{\mathrm{s}}$ and recalculates $1 / r_{\mathrm{s}}$ from $M=15 \frac{1}{4} \mathrm{~h}$ (F52.1) by means of $\varepsilon_{\mathrm{h}}, \varepsilon_{\mathrm{m}}$ and $\varepsilon_{r}$ (cf. Sections 2.1 and 2.4), but does not recover 120/41 $\frac{4}{5} .{ }^{13}$ Following [Rawlins 2009], it is assumed here that $r_{\mathrm{s}}$ is the result of a real measurement which Pytheas performed in Massalia. Hence, $\varepsilon=23^{\circ} 44^{\prime}$ of Pytheas' time is used for conversion (15).

F56 (G II.5.41): "If one sails into the Pontus [Black Sea] and proceeds about 1,400 stades [F56.1] northwards, the longest day becomes $15 \frac{1}{2}$ equinoctial hours [F56.2]." The distance refers to the parallel of Byzantium (cf. [Dicks 1960, p. 183]). Furthermore, the mentioned region in the Pontus (Mid-Pontus) is "... equidistant from the pole and the equator ..." so that $b_{0}=C / 8=31,500$ st (cf. (1)) is used (F56.3). Moreover, there "... the arctic circle is in the zenith ..." (i.e. only one point of the circle). Hence, its declination $\delta_{\mathrm{a}}$ equals $\phi$ and (6) yields $\phi=90^{\circ} / 2=$ $45^{\circ}$ or $b_{0}=C / 8$, which is not introduced here once more.

F57 (G II.5.42): Strabo reports on the neighborhood of the Borysthenes and the southern parts of Lake Maeotis: "The northern part of the horizon, throughout almost the whole of the summer nights, is dimly illuminated by the sun $[\ldots]$; for the summer tropic is seven-twelfths of a zodiacal sign from the horizon $\left[=a_{\mathrm{t}}\right]$, and therefore this is also the distance that the sun is below the horizon at midnight $[=\alpha]$." One zodiacal sign corresponds to $360^{\circ} / 12=30^{\circ}$ and $\frac{7}{12}$ of a sign is $17^{\circ} 30^{\prime}$. The text suggests that the angles $a_{\mathrm{t}}$ and $\alpha$ refer to the summer solstice, that $a_{\mathrm{t}}$ is $17^{\circ} 30^{\prime}$ and that $\alpha$ equals $a_{\mathrm{t}}$. Figure 4 shows the meridian $\mathrm{m}$, equator e and positions $\mathrm{D}$ and $\mathrm{N}$ of the observer at noon and midnight, respectively, at the summer (a) and winter (b) solstices. Shifting the horizon $h_{D}$ in the center $C$ of the earth to position $\mathrm{h}_{\mathrm{D}}^{\prime}$, the circle $\mathrm{m}$ can be regarded as the celestial sphere. Then, the sun's altitude $a_{\mathrm{s}}$ at $\mathrm{C}$ in Figure 4(a) and the angle $\alpha_{\mathrm{w}}$ at $\mathrm{C}$ in (b) correspond to Strabo's description of $a_{\mathrm{t}}$ and $\alpha_{\mathrm{s}}$ at $\mathrm{N}$ in (a) and $\alpha_{\mathrm{w}}$ at $\mathrm{N}$ in (b) correspond to Strabo's description of $\alpha$. Since $\alpha_{\mathrm{s}} \neq a_{\mathrm{s}}$, Strabo's equation $\alpha=a_{\mathrm{t}}$ holds true for the winter solstice only. For the summer solstice, $a_{\mathrm{s}}=90^{\circ}-\phi+\varepsilon \approx 64^{\circ} 57^{\prime}$ (equation (12) with $b_{0}=34,100 \mathrm{st}$ of Lake Maeotis; cf. Section 3.2) applies, which is inconsistent with the given value $17^{\circ} 30^{\prime}$ of $a_{\mathrm{t}}$. The altitude $a_{\mathrm{w}}=90^{\circ}-\phi-\varepsilon \approx 17^{\circ} 37^{\prime}$ (equation (13)) of the

${ }^{13}$ To test the possibility of an ancient conversion from $M$ to $r_{\mathrm{s}}$, Jones' conversion is redone here with different calculation steps. The original conversion from $M$ to $\phi$ was presumably based on $\varepsilon_{\mathrm{h}}$ ([Diller 1934]). Its result was probably rounded to the nearest twelfth of a degree: $\phi_{\mathrm{t}}(M)=43^{\circ} 17^{\prime} \approx$ $43^{\circ} 15^{\prime}$. The conversion from $\phi$ to $r_{\mathrm{s}}$ is based on (15), the determination of $\tan (\phi-\varepsilon)=\tan \alpha$. As can be expected from ancient calculations, the tangent function was determined by the ratio $\operatorname{crd}(2 \alpha) / \operatorname{crd}\left(180^{\circ}-2 \alpha\right)$ (following from $2 \sin \alpha=\operatorname{crd} 2 \alpha$; see [Neugebauer 1975, pp. 21-24]). The chord $\operatorname{crd}()$ is determined here by a linear interpolation of Hipparchus' presumed table of chords, reconstructed in [Toomer 1974]. The results based on $\varepsilon_{\mathrm{h}}, \varepsilon_{\mathrm{m}}$ and $\varepsilon_{\mathrm{r}}$ are $\approx 42.69 / 120, \approx 42.25 / 120$, and $\approx 41.91 / 120$. The numerator, however, should be within the interval $[41.7,41.9]$ if it is to be expressed as $41 \frac{4}{5}$. 


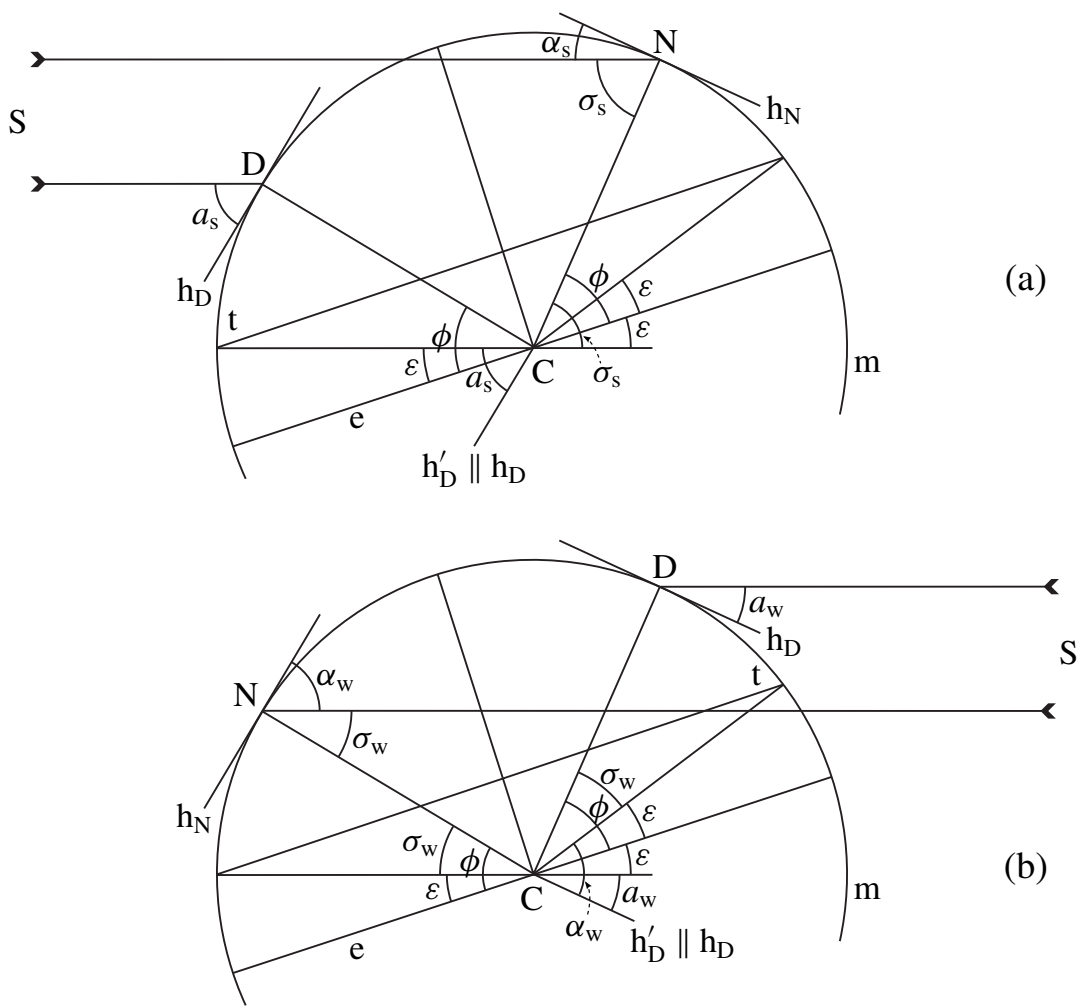

Figure 4. On Strabo's information on Lake Maeotis in fragment F57: (a) summer solstice; (b) winter solstice (e: equator, $\mathrm{h}_{\mathrm{D} / \mathrm{N}}$ : horizon at noon/midnight, $\mathrm{m}$ : meridian, $\mathrm{S}$ : sun, t: tropic).

winter solstice, however, is consistent with the value of $a_{\mathrm{t}}$ but inconsistent with Strabo's description of $a_{\mathrm{t}}$. Figure 4(a) yields $\alpha_{\mathrm{s}}=90^{\circ}-\sigma_{\mathrm{s}}=90^{\circ}-\phi-\varepsilon=a_{\mathrm{w}}$ via (13), while (b) gives $\alpha_{\mathrm{w}}=90^{\circ}-\sigma_{\mathrm{w}}=90^{\circ}-\phi+\varepsilon=a_{\mathrm{s}}$ via (12). In summary, Strabo's information can be corrected by the following two statements. First, $a_{\mathrm{t}}$ is (about) $65^{\circ}$ at the winter solstice and equals $\alpha$ at the winter solstice $\left(=\alpha_{\mathrm{w}}\right)$. Second, $a_{\mathrm{w}}$ is $17^{\circ} 30^{\prime}$ and equals $\alpha$ at the summer solstice $\left(=\alpha_{\mathrm{s}}\right)$. Nonetheless, Strabo's information is not used further.

F60.1 (G II.5.42): Gosselin [1798, p. 28], ${ }^{14}$ Berger [1869, p. 70] and Diller [1934] notice that $b=6,300$ st for Byzantium - "north of Lake Maeotis" is 1,400 st $\left(2^{\circ}\right)$ too small in comparison to the $M$-data of these locations (F52.1: $15 \frac{1}{4} \mathrm{~h}, \mathrm{~F} 60.3: 17 \mathrm{~h}$ ). Diller [1934] assumes that Strabo inadvertently used Mid-Pontus (F56.2: $M=$ $15 \frac{1}{2} \mathrm{~h}$ ) instead of Byzantium for the calculation of $b$. Accordingly, the corrected $b=7,700$ st is used here.

${ }^{14}$ I thank a referee for mentioning [Gosselin 1798] in the context of the errors of F60.1 and F61.3. 
F61.1 (G II.1.18): Dicks [1960, p. 185] shows that $b=6,300$ st of Massalia Celtica (according to Hipparchus, but according to Strabo north of Celtica) has also an error of $2^{\circ}$ as $b$ of F60.1. It is corrected to 7,700 st here.

F61.3 (G II.1.18): $b=9,100$ st of Massalia - 18 h-region has the same error of $2^{\circ}$ as $b$ of F60.1 ([Gosselin 1798, p. 28; Berger 1869, p. 70; Diller 1934]). The corrected $b=10,500 \mathrm{st}$ is applied here.

F63 (CP I.3.7): Hipparchus refers to regions at the Hellespont. These regions are equated here with Alexandria in the Troad. Hipparchus gives $M / m=\frac{5}{3}$ and $M=15 \mathrm{~h}$. Since both are equivalent, only the latter is used here.

F65.1 (CP I.4.8): Hipparchus says that $\zeta_{\mathrm{a}}$ is about $37^{\circ}$ in the environment of Athens and wherever $r_{\mathrm{e}}$ equals $\frac{4}{3}$. Although he does not explicitly assign this $r_{\mathrm{e}}$ to Athens, it is used here for Athens.

F66.1, F67.1, F71.1 (CP I.7.11, I.7.14, II.4.2): Hipparchus gives the same data for the culmination, rising and setting of constellations for Greece as for the regions where $M=14 \frac{1}{2} \mathrm{~h}$. Thus, this $M$ value is assigned to Greece here.

3.2. Test of consistency. The consistency of the data ascribed to Hipparchus is tested according to Section 2.2. The $n=84$ data $b_{i}$ given in Table 2 are composed to the equation system (4). The imprecise $a_{\mathrm{w}}$ of F61.5 is not involved in the adjustment computation. Furthermore, the $M$-data of F66.1, F67.1 and F71.1 are not used because probably they are imprecise values (see below). There remain $n=80$ data for the adjustment computation. The system (4) has 34 unknown $b_{0}$ of the locations shown in Figure 3 (for Celtica only one $b_{0}$ is used). The $L_{1}$-norm adjustment by means of the BR-algorithm yields $61 v_{i}$ being 0 ; hence, the related data are consistent among each other. The nonzero $v_{i}$ are considered below. It turns out that the solution for the $b_{0}$ can be regarded as being in accord with Hipparchus' original data. The $b_{0}$ are given in Figure 3 .

F15.1; Meroë - Byzantium; $b \approx 18,000$ st; $v=500$ st: 18,000 st are contradictory to $b=18,500 \mathrm{st}$, which follows from $b_{0}$ of F43.2 (Cinnamon country), $b_{0}$ of F52.3 (Byzantium) and $b$ of F43.2/44.1 (Cinnamon country - Meroë). Since, however, Strabo gives "about" 18,000 st, there is not a real contradiction.

F47.3; Syene; sun at zenith at summer solstice $\Rightarrow b_{0}=16,602 \mathrm{st} ; v=198 \mathrm{st}: b_{0}$ was derived from $\phi=23^{\circ} 43^{\prime}=\varepsilon$ (Section 3.1); it is contradictory to $b_{0}=16,800 \mathrm{st}$ which follows from $b_{0}$ of F43.2 (Cinnamon country), $b$ of F43.1 (Cinnamon country - Meroë) and $b$ of F43.3 (Meroë - Syene). The value 16,800 st corresponds to $\phi=24^{\circ}$, in good agreement with the real $\phi=24^{\circ} 05^{\prime}$. Thereby, it equals the common ancient value $\varepsilon_{\mathrm{r}}$ so that Syene was theoretically located on the tropic. Nonetheless, the information of F47.3 may be based on a real observation. Owing 
to the closeness to the tropic, the sun's altitude was about $90^{\circ}$ at noon on the summer solstice, so that for an observer the sun apparently stood at the zenith. ${ }^{15}$

F48.6; Carthage; $r_{\mathrm{e}}=\frac{11}{7} \Rightarrow b_{0}=22,730 \mathrm{st} ; v=-30 \mathrm{st}$ : $b_{0}$ of F48.3 (Alexandria klima) and $b$ of F48.5 (Alexandria klima - Carthage) as well as $M$ of F49.2 (Ptolemais in Phoenicia) and $b$ of F49.4 (Carthage - Ptolemais) yield $b_{0}=22,700$ st for Carthage. If this value was calculated from $\phi$ and rounded to the nearest 100 st, the original $b_{0}$ should be within the interval $[22,650 \mathrm{st}, 22,750 \mathrm{st}]$. This is fulfilled by the $b_{0}$ derived from $r_{\mathrm{e}}$. Hence, $r_{\mathrm{e}}$ could have been calculated from $\phi$.

F50.5; Alexandria - Rhodes (center); $b=3,640 \mathrm{st} ; v=-40 \mathrm{st}$ : $b$ is contradictory to the value 3,600 st, which follows from $b=7,000$ st of F51.5 (Alexandria - Alexandria in the Troad) and $b=3,400$ st of F51.7 (Rhodes - Alexandria in the Troad). Diller [1934] assumes an error of $40 \mathrm{st}$ in $b=3,640$ st originating from a faulty reading. Berger $[1869$, p. 53] states that the value of 3,640 st is given with a higher precision and that it refers to the city of Rhodes. Dicks [1960, p. 176] considers $b$ to be derived from a real measurement by Hipparchus in the center of Rhodes and assumes that the text originally gave 3440 st. Shcheglov [2007] assumes that both 3,600 st and 3,640 st are authentic and that they refer to the center of Rhodes and the city of Rhodes, respectively. The following explanation shall be added. In F50 Strabo refers not only to the center of Rhodes but to "... the regions round the center of Rhodes ..." and states that there $M$ is $14 \frac{1}{2} \mathrm{~h}$. Hipparchus assigned a $\phi$ value to the $14 \frac{1}{2} \mathrm{~h}$ klima, which probably was $\phi_{1}=\phi_{\mathrm{t}}(M)=36^{\circ} 15^{\prime}$. Strabo converted $\phi_{1}$ into $b_{0}$ and rounded it to the nearest 100 st: $b_{01}\left(\phi_{1}\right)=25,375 \mathrm{st} \approx 25,400$ st. Strabo had a further value $\phi_{2}$ for the city of Rhodes in the north of the island (e.g., from Hipparchus, who lived on the island of Rhodes); it corresponded to $b_{02}=25,440 \mathrm{st}$ $\left(=3640 \mathrm{st}+21800 \mathrm{st}\right.$ of Alexandria), i.e. $\phi_{2} \approx 36^{\circ} 21^{\prime}$. (That value is somewhat less than the real $\phi=36^{\circ} 26^{\prime}$ and therefore consistent with the ancient systematic error of a gnomon measurement due to the generation of the shadow by the upper edge of the sun; see Section 3.) Strabo knew that $M \approx 14 \frac{1}{2} \mathrm{~h}$ is valid in a wide area, that $\phi_{1}$ is a theoretical value derived from $M$ and that his rounding up of $b_{01}$ yielded a less accurate and more northerly position (as $b_{02}$ ). Furthermore, $b_{01}$ and $b_{02}$ only differ by 40 st. Thus, Strabo chose the more precise and trustable $b_{02}$ for his statement in F50 on the $14 \frac{1}{2} \mathrm{~h}$ klima.

F52.2; Byzantium; $r_{\mathrm{s}}=120 / 41 \frac{4}{5} \Rightarrow b_{0}=30,243 \mathrm{st} ; v=57 \mathrm{st}: r_{\mathrm{s}}$ is assumed to be the result of an independent measurement (cf. Section 3.1); nevertheless, the small $v$ shows that $r_{\mathrm{s}}$ is in accord with the other data.

${ }^{15}$ For $220-120$ BC, the maximal altitude of the sun at the summer solstice was determined based on the calculation method given in Fn. 4 ; the result is $89^{\circ} 37^{\prime} \approx 90^{\circ}$. 
F56.3; Mid-Pontus; $b_{0}=C / 8 \Rightarrow b_{0}=31,500 \mathrm{st} ; v=200 \mathrm{st}: b$ is contradictory to $b_{0}=31700$ st, which follows, for instance, from $M$ of Mid-Pontus (F56.2). However, $v$ is acceptable because $b_{0}$ of F56.3 is derived from rough information (cf. Section 3.1).

F57.4; Lake Maeotis; $a_{\mathrm{w}}=9 \mathrm{c} \Rightarrow b_{0}=33,833 \mathrm{st} ; v=267$ st: Since $a_{\mathrm{w}}$ is a rounded value, it can be regarded as consistent with the other data if $v$ is $<0.5 \mathrm{c}=$ $1^{\circ} \widehat{=} 700$ st. That is fulfilled.

F58.2; Borysthenes; $a_{\mathrm{w}}=9 \mathrm{c} \Rightarrow b_{0}=33,833 \mathrm{st} ; v=167$ st: Cf. F57.4.

F60.2; "north of Lake Maeotis"; $a_{\mathrm{w}}=6 \mathrm{c} \Rightarrow b_{0}=38,033$ st; $v=-33$ st: Cf. F57.4. $a_{\mathrm{w}}$ is consistent with $b_{0}=38,000 \mathrm{st}$, which follows from $b_{0}$ of F52.4 (Byzantium) and the corrected $b=7,700$ st of F60.1 (Byzantium - "north of Lake Maeotis").

F61.1; Massalia - Celtica; $b=7,700 \mathrm{st} ; v=-4,000 \mathrm{st}: b$ is contradictory to the value 3,700 st, which follows from $b$ of F59.2 (Massalia - Borysthenes) and $b=0$ of F58.1/59.3 (Borysthenes - Celtica). From F61.1 and $b_{0}=30,300$ st of Massalia follows $b_{0}=38,000 \mathrm{st}$ for Celtica in contrast to $b_{0}=34,000 \mathrm{st}$, which follows from F59.2 and F58.1/59.3. This is not a real contradiction because Celtica is a region with a large latitudinal extent and Hipparchus did not distinguish between the Celtic and the Germanic coasts (see [Dicks 1960, pp. 185, 188]), so he gave a southern (F58.1, F59.3) and a northern (F61.1, F61.2) latitude for Celtica. This becomes evident from Strabo's statement (F61/G II.1.18) that Hipparchus takes the inhabitants of the region concerning F61.1 "... to be still Celts ..." and that Strabo himself considers them as "... Britons who live 2,500 stades north of Celtica ..." ("Celtica" refers to Hipparchus' southern latitude). Strabo's $b=2,500$ st must be corrected by $+2^{\circ} \widehat{=} 1,400$ st as $b$ of F61.1 (see Section 3.1). Then, $b_{0}$ for the northern latitude of Celtica is $(34,000+2,500+1,400) \mathrm{st}=37,900 \mathrm{st}$, in accordance with 38,000 st derived from F61.1.

F61.2; Celtica; $a_{\mathrm{w}}=6 \mathrm{c} \Rightarrow b_{0}=38,033 \mathrm{st} ; v=-4,033$ st: As F61.1 (Massalia Celtica), $a_{\mathrm{w}}$ refers to the northern latitude of Celtica at $b_{0}=38,000$ st. The $v$ in this regard is only -33 st, which is acceptable; cf. F57.4.

F61.4; 18 h-region; $a_{\mathrm{w}}=4 \mathrm{c} \Rightarrow b_{0}=40,833 \mathrm{st} ; v=-33$ st: Cf. F57.4.

F61.5; "inhabited region"; $a_{\mathrm{w}}<3 \mathrm{c} \Rightarrow b_{0}>42,198 \mathrm{st} ; v=567$ st: The information $b_{0}>42,198$ st is in accord with $v>0$ and $v$ is acceptable because of the imprecise data; therefore, F61.5 is consistent.

F62.1, F65.1; Greece, Athens; $r_{\mathrm{e}}=\frac{4}{3} \Rightarrow b_{0}=25,809 \mathrm{st} ; v=91 \mathrm{st}$ : From $r_{\mathrm{e}}$ and (14) follows $\phi=36^{\circ} 52^{\prime}$. Thus, $r_{\mathrm{e}}$ is consistent because it is in accord with the latitude of $37^{\circ}$, which follows from F62.3, F69.1 (Greece) as well as from F64.2, F65.2, F68.1, F70.1 (Athens). 
F62.2, F64.1; Greece, Athens; $M=14 \frac{3}{5} \mathrm{~h} \Rightarrow b_{0}=26,024 \mathrm{st} ; v=-124 \mathrm{st}$ : The latitude $\phi_{\mathrm{t}}\left(M, \varepsilon_{\mathrm{h}}\right)$ is $37^{\circ} 18^{\prime}$. The difference to $37^{\circ}$ of F62.3, F69.1 (Greece) as well as of F64.2, F65.2/70.1, F68.1 (Athens) is $18^{\prime}$. Shcheglov [2007] considers $37^{\circ}$ as inconsistent with $\varepsilon_{\mathrm{h}} . \phi_{\mathrm{t}}\left(M, \varepsilon=23^{\circ} 51^{\prime}\right)=37^{\circ} 03^{\prime}$ is in better agreement, so Dicks [1960, p. 167] assumes $23^{\circ} 51^{\prime}$ (MS I.12) to be Hipparchus' value for $\varepsilon$. However, $\varepsilon_{\mathrm{h}}$ need not be refused. First, Hipparchus only gives "about $37^{\circ}$ " in F62.3 (Greece) as well as in F64.2, F65.2, F70.1 (Athens). Second, Hipparchus usually uses a step width of $\frac{1}{4} \mathrm{~h}$ or a multiple of it for his klimata; the nearest $M$ values $14 \frac{1}{2} \mathrm{~h}$ and $14 \frac{3}{4} \mathrm{~h}$ yield $36^{\circ} 15^{\prime}$ and $38^{\circ} 47^{\prime}$ so that $14 \frac{3}{5} \mathrm{~h}$ represents a good fit with $37^{\circ}$ and can be regarded as consistent. Moreover, Hipparchus assigns $14 \frac{3}{4}$ h (F62.2) as well as $14 \frac{1}{2}$ h (e.g., F66.1) to Greece, which illustrates Hipparchus' low demand for the accuracy of the $M$-data.

F63.1; Alexandria in the Troad; $M=15 \mathrm{~h} \Rightarrow b_{0}=28,753 \mathrm{st} ; v=47 \mathrm{st}: M$ is consistent; it is in agreement with F51.4.

F63.2; Alexandria in the Troad; $\phi=a_{\mathrm{p}} \approx 41^{\circ} \Rightarrow b_{0} \approx 28,700 \mathrm{st} ; v=100 \mathrm{st}: v$ is acceptable because of the approximate $a_{\mathrm{p}}$ so that F63.2 is consistent.

F66.1, F67.1, F71.1; Greece; $M=14 \frac{1}{2} \mathrm{~h} \Rightarrow b_{0}=25,308 \mathrm{st} ; v=592 \mathrm{st}: M$ is contradictory to $M=14 \frac{3}{5} \mathrm{~h}$ of F62.2. The smaller $M=14 \frac{1}{2} \mathrm{~h}$ leads to a region south of Athens because Hipparchus assigns $M=14 \frac{3}{5}$ h to Athens (F64.1). Hipparchus probably only gives a less accurate $M$ value with a resolution of $\frac{1}{2} \mathrm{~h}$ in F66.1, F67.1, F71.1.

F70.2; Rhodes; $\zeta_{\mathrm{a}}=36^{\circ} \Rightarrow b_{0}=25,200 \mathrm{st} ; v=200$ st: From $M=14 \frac{1}{2} \mathrm{~h}$ of F50.4 follows $\phi_{\mathrm{t}}(M)=36^{\circ} 15^{\prime}$. Hence, $\zeta_{\mathrm{a}}$ of F70.2 is probably only a rough value as $a_{\mathrm{p}}$ of Athens of F64.2.

Since the $a_{\mathrm{w}}$-data of F60.2, F61.2 and F61.4 are inconsistent with the uncorrected textual $b$ values of F60.1, F61.1 and F61.3 (see Section 3.1), they confirm that the error of 1400 st of these $b$ values is caused by Strabo.

In F51 Strabo assigns Alexandria in the Troad to the parallel which has $M=15 \mathrm{~h}$ (F51.4) and is "over 28,800 st" from the equator (F51.6). From $M$ follows $\phi_{\mathrm{t}}(M) \approx$ $40 \frac{1}{6}^{\circ} \widehat{=} 28,817 \mathrm{st} \approx 28,800$ st (which corresponds to the result of the adjustment). In his statement Strabo possibly refers to the value of 28,817 st, which resulted from his conversion of $\phi$ into $b_{0}$.

According to F53 the parallel through the mouth of the Borysthenes runs through Britain too (F53.1). It is likely that Hipparchus referred to Celtica and Strabo replaced it by Britain (likewise [Berger 1869, p. 66, footnote 1]) for the following reasons. First, according to F58.1/59.3 (G II.1.18/12) Hipparchus locates Celtica and the Borysthenes at the same latitude. Second, according to F61 (G II.1.18) Hipparchus locates Britain north of the "inhabited region"/19 h parallel, and so 
much further north than the Borysthenes. Finally, according to F61 Strabo believes the Celts mentioned by Hipparchus to be Britons.

Dicks [1960, p. 184] assumes that Strabo's data on the Borysthenes including F57 always refer to its mouth. There is, however, evidence that Hipparchus located the mouth of the Borysthenes further south than the regions assigned to the $16 \mathrm{~h}$ klima (F57). Strabo explicitly states that Hipparchus locates the mouth 3,700 st north of Massalia and Byzantium (F59.1, F59.2) and 34,000 st north of the equator (F59.4); from the former value also follows $b_{0}=34,000$ st. Furthermore Strabo says that $M$ is $16 \mathrm{~h}$ in the regions in the neighborhood of the Borysthenes and the southern parts of Lake Maeotis (F57.2), which are 3,800 st north of Byzantium (F57.1) and 34,100 st north of the equator (F57.3); from the former $b$ value also follows $b_{0}=34,100$ st. The $b$-data are confirmed by $\phi_{\mathrm{t}}(M) \approx 48 \frac{9}{12}^{\circ} \widehat{=} 34125 \mathrm{st} \approx$ 34,100 st. Hence, Hipparchus distinguished between the mouth of the Borysthenes and the $16 \mathrm{~h}$ klima, which is $100 \mathrm{st}$ further north.

\section{Summary}

The latitudinal data attributed to Eratosthenes and Hipparchus were each compiled and formulated as systems of equations, whose solution revealed the differences and inconsistencies of the data. As a result, the presumably original data of Eratosthenes and Hipparchus were deduced.

The analysis of the data ascribed to Eratosthenes showed several disagreements, which suggests that the data concerned originate from Strabo and not from Eratosthenes; this applies to F34.9, F34.10, F34.11, F35.5, F35.6, F36.2 and F47.1. In particular, Eratosthenes' latitudinal extent of the inhabited world up to the "northern regions" (F30.1, F34.12) is in contradiction with the corresponding sum of the given meridian arc lengths ascribed to Eratosthenes so far. Therefore, Eratosthenes' meridian arc length of the part Borysthenes - "northern regions" is probably not 4,000 st (F34.9) but 3,000 st, which is given by Strabo in G II.5.8 (F34.13).

Eratosthenes' latitudinal distances Alexandria - Hellespont - Borysthenes (F35.2, F35.3/36.3) are grossly erroneous. According to Strabo it was generally agreed that the sea route Alexandria - Borysthenes is a straight line. Hence, Eratosthenes presumably based his latitudinal distances Rhodes - Hellespont - Byzantium on the lengths of sea routes, which is affirmed by a good agreement of his distances with the actual distances alongside the Turkish coast.

From Pytheas' information on the position of the arctic circle relating to Thule it was known that Thule is situated at a latitude of $\left(90^{\circ}-\varepsilon\right)$, where $\varepsilon$ is the obliquity of the ecliptic. In conjunction with Eratosthenes' latitudinal data for Thule, $23^{\circ} 40^{\prime}$ can be derived for Eratosthenes' value of $\varepsilon$. This value corresponds to Hipparchus' 
presumable value (see [Diller 1934]) and was possibly referred to by Ptolemy in MS I.12.

The fragments ascribed to Hipparchus contain latitudinal quantities of different types. Occurring differences of the data were explained by the different types of information and their different precision and origination. The real inconsistencies can be ascribed to Strabo in most cases; this applies to F48.4 (e.g., [Neugebauer 1975]), F60.1 and F61.3 ([Diller 1934]), F61.1 ([Dicks 1960]), F15.1, F51.6, F53.1 and F57. Strabo's statement on the distances of the summer tropic and the sun with respect to the horizon at Lake Maeotis in F57 has not been interpreted so far; his error in this regard was illustrated. Hipparchus distinguished between the $14 \mathrm{~h}$ klima and the city Alexandria as well as between the $13 \mathrm{~h}$ klima and the city of Meroë ([Rawlins 2009]). The present investigation revealed that Hipparchus probably also distinguished between the $16 \mathrm{~h}$ klima and the mouth of the Borysthenes 100 st south of the parallel of the klima.

\section{Appendix: On the location of Thule}

Pytheas' voyage to Thule took place in ca. $330 \mathrm{BC} .{ }^{16}$ His treatise On the Ocean on his voyages is not preserved, but later ancient authors provided extractions thereof. The handed down information on Thule is given in [Hennig 1944, pp. 155-159] and [Whitaker 1982], for example. The main sources are Strabo's Geography and Pliny's Natural History. The only quotation from Pytheas' treatise is to be found in Geminus' Eisagoge (E; see [Manitius 1898]). Ptolemy also describes the position and form of the island of Thule by means of longitudes and latitudes in GH II.3.

The two common localizations for Pytheas' Thule are Iceland (e.g., [Burton 1875; Roller 2010, p. 127]) and Norway. Iceland is neglected here because Pytheas met inhabitants in Thule according to E VI.9, but so far a settlement of Iceland cannot be assumed for his time. Nansen [1911, p. 62] and Hennig [1944, p. 166] locate Thule in the region of Trondheim in Norway.

Ptolemy does not refer to Pytheas' Thule; his island of Thule is usually identified as Shetland (e.g., [Rivet and Smith 1979, p. 146]). Detailed reasons for this are given in [Marx 2014] in an investigation of Ptolemy's coordinates of Scotland. It should be added that Ptolemy's length of $20 \mathrm{~h}$ for the longest day in Thule (GH VIII.3.3, MS II.6) contradicts Pytheas' information on the length of the nights in Thule (see below).

For a localization of Pytheas' Thule, the following information comes into consideration:

1. Thule is a six-day seafaring from Britain in a northern direction (G I.4.2, NH II.77).

${ }^{16}$ [Nansen 1911, p. 48]: 330-325 BC; [Hennig 1944, p. 162]: 350-310 BC. 
2. In the region of Thule the tropic of Cancer coincides with the arctic circle (G II.5.8). At the summer solstice there are no nights (NH IV.30).

3. The meridian arc length $b$ of Borysthenes - Thule is 11,500 st (G I.4.2).

4. Pytheas said that in Thule the length $n$ of the nights was $2 \mathrm{~h}$ and $3 \mathrm{~h}$ (E VI.9).

5. A day's journey away from Thule is the frozen/clotted sea (NH IV.30).

The frozen/clotted sea suggests a larger appearance of sea ice. That disagrees with the location of Thule in Norway because in the Norwegian Sea there is no drift ice (cf. [Vinje and Kvambekk 1991]) and at Pytheas' time, at the beginning of the Subatlantic, the climate was similar to today's climate so that drift ice can be excluded. According to [Hennig 1944, pp. 105, 156, footnote 1] the clotted sea is a fiction, which can be found similarly in ancient and medieval literature. Thus, information 5 does not play a role here.

Information 2 and 3 are treated in Section 2.4; information 1 and 4 are dealt with in the following.

Casson [1971, pp. 281-96] determines the speeds of reported ancient seafarings; the speeds under favorable winds were about 3.5 to $6 \mathrm{kn}$ and under unfavorable winds about 1.5 to $3 \mathrm{kn}$. Assuming favorable conditions but a moderate average speed of about $3.5 \mathrm{kn}=156 \mathrm{~km} / \mathrm{d}$ for Pytheas' voyage, the time of six days (i.e. days and nights) corresponds to about $940 \mathrm{~km}$, which is used here. According to Pliny (NH IV.30) one traveled from the island called Berrice (also named Nerigos in the manuscripts) to Thule. Berrice is possibly the island Mainland of Shetland; cf. [Nansen 1911, p. 61] and [Hennig 1944, p. 156]. The starting point of the sixday journey to Thule, however, was rather located at Great Britain, since Thule “... is six days' sail from the north of Britain ..." ([Bostock and Riley 1855]) according to NH II.77 ([1985, p. 136], for example, chooses Cape Wrath for the starting point). NH IV.30 suggests that Berrice/Mainland of Shetland was on Pytheas' way to Thule, which is taken into account here. For the starting point of the time measurement of the six-days journey Duncansby Head is assumed here. Figure 5 shows two possible sea routes with a length of $940 \mathrm{~km}$ from Great Britain to Thule. Both routes bypass Orkney and Mainland. From there, route A takes course directly to the West Cape of Norway and continues alongside the Norwegian coast up into the Trondheimsfjord. Route B takes course eastwards along a constant latitude to the Norwegian coast at Bergen and continues alongside the coast up to the island Smøla. This route assumes latitude sailing was used, which was an easy and common method for navigation (it was used, e.g., by the Vikings later on; cf. [Johnson 1994]). Hennig [1944, p. 167] rejects the similar route Orkney - Bergen because in his opinion the eastern course contradicts the position of Thule north of Britain. If, however, Pytheas visited a northern region of Norway and only referred the name Thule to this region, there is no contradiction. Owing to the 


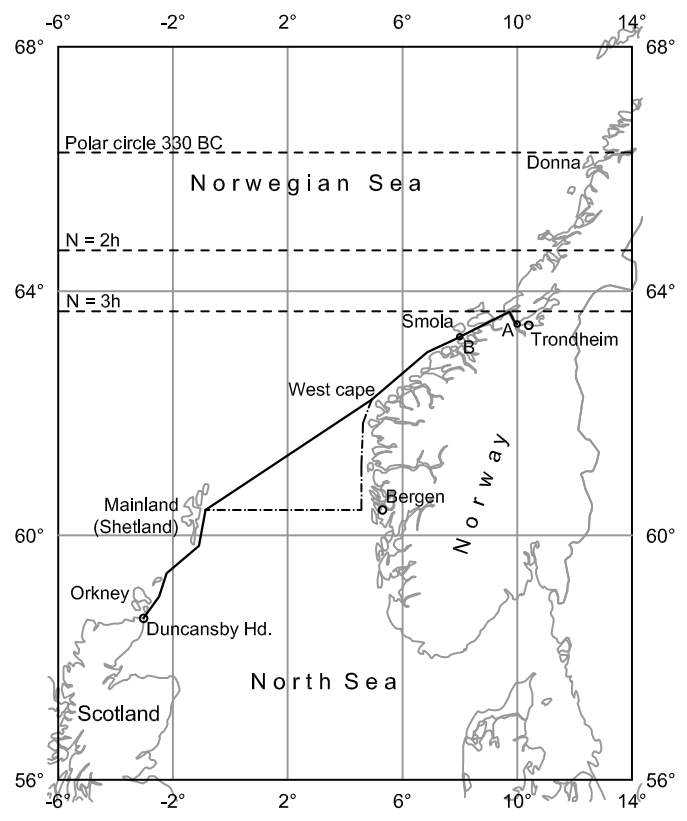

Figure 5. Pytheas' possible sea route from Great Britain to Thule; solid line $=$ route $\mathrm{A}$, dashed line $=$ portions where route $\mathrm{B}$ departs from route $\mathrm{A}$.

uncertainty of the assumed speed and way, Pytheas' landing point cannot be given precisely. The Trondheimsfjord and the coastal region of the same latitude come into consideration.

Before Geminus quotes Pytheas in E VI.9 he discusses $M$-data of different latitudes. Thus, [Nansen 1911, p. 57] assumes that Pytheas' information on the length of the nights refers to the shortest nights of the year. This, however, does not result directly from the text. For Pytheas' time the lengths of the nights were determined; the year $330 \mathrm{BC}$ was used, other supposable times do not yield significant differences. The shortest nights (at summer solstice) with lengths $N=2 \mathrm{~h}, 3 \mathrm{~h}$ occurred at $\phi=64^{\circ} 40^{\prime}$ and $\phi=63^{\circ} 40^{\prime}$, respectively. ${ }^{17}$ These latitudes are significantly less than $\phi=66^{\circ} 16^{\prime}$ of the polar circle and thus inconsistent with the information on the arctic circle (see Section 2.4); see also Figure 5. In Geminus' quotation it is only said that the night was very short so that the given lengths of nights may refer

${ }^{17}$ For a location of latitude $\phi$ and for a given time $t$, the length $n$ of the night can be determined by the following calculation steps (according to [Strous 2012]; applied formulas see [Meeus 1991, pp. 98, 135, 151-153]; cf. also footnote 4): $\varepsilon=\varepsilon(t) ; M(t) ; L_{0}=L_{0}(t) ; C=C(t, M) ; \Theta=\Theta\left(L_{0}, C\right)$; $\delta=\delta(\Theta, \varepsilon)$; hour angle at sunset: $H=H\left(\phi, \delta, a_{0}\right) ; n=24 \mathrm{~h}-2 H$. By means of the altitude $a_{0}=-50^{\prime}$ the atmospheric refraction and the size of the sun disc are taken into account. For the determination of $\phi$, it was varied till $n$ equaled the given value. 


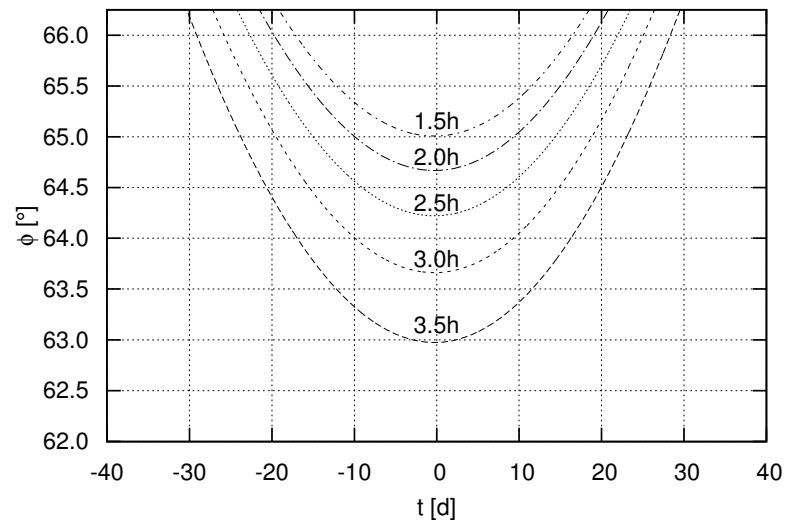

Figure 6. Isolines of the length $n$ of the night subject to the latitude $\phi$ and time $t$ expressed by the number of days since the summer solstice in $330 \mathrm{BC}$.

to a date near the summer solstice. In order to locate the associated region, the length $n$ of the night was determined for different latitudes $\phi$ and times $t$. Figure 6 shows the result in form of isolines of $n$. At $\phi=63^{\circ} 20^{\prime} n, n=3.3 \mathrm{~h} \approx 3 \mathrm{~h}$ five days before/after the summer solstice. Thus, the southern limit for Pytheas' Thule can be located at this latitude, which corresponds to the latitude of the southern end of the Trondheimsfjord. At the polar circle, at $\phi=66^{\circ} 16^{\prime}, n \approx 2 \mathrm{~h}$ twenty-two days before/after the summer solstice. Possibly, Pytheas traveled to this region at that time, where he heard about the midnight sun.

Pytheas' information on the arctic circle and Eratosthenes latitudinal data lead to the northern polar circle at $\phi=66^{\circ} 16^{\prime}$ at Pytheas' time. Pytheas' information on the journey length suggests the region at the latitude of the southern end of the Trondheimsfjord. His information on the length of the nights leads to both of these regions. This is not contradictory because the name Thule may refer to a region of larger extent. Hence, Pytheas' Thule can be equated with the region of Norway west of the Scandinavian Mountains between about $63^{\circ} 20^{\prime}$ and $66^{\circ} 16^{\prime}$ latitude. This result is in accordance with Pytheas' contact with inhabitants and his report on the cultivation of grain in Thule (G IV.5.5). In the said region there are spacious low-lying areas and a warm and humid climate influenced by the North Atlantic Current. Apart from the southern regions at the Skagerrak, in Norway there are only low-lying areas with fertile clayey soils at the Trondheimsfjord (see [Sporrong 2008, p. 26, fig. 6]). According to [Helle 2008, pp. 7-8] there were stable settlements and farming in Norway as far north as Trøndelag at the beginning of the Iron Age (500 BC - $800 \mathrm{AD})$. Furthermore, in regions at the polar circle agriculture 
was introduced in the 7th and 4th century BC as revealed by radiocarbon dating based on pollen (see [Johansen and Vorren 1986]).

\section{References}

[Barrodale and Roberts 1974] I. Barrodale and F. D. K. Roberts, "Algorithm 478: solution of an overdetermined system of equations in the $\mathrm{L}_{1}$ norm", Commun. ACM 17:6 (1974), 319-320.

[Berger 1869] H. Berger, Die geographischen Fragmente des Hipparch, Teubner, Leipzig, 1869.

[Berger 1880] H. Berger, Die geographischen Fragmente des Eratosthenes, Teubner, Leipzig, 1880.

[Bostock and Riley 1855] J. Bostock and H. Riley (editors), The natural history of Pliny, Bohn, London, 1855.

[Bunbury 1879] E. H. Bunbury, A history of ancient geography among the Greeks and Romans from the earliest ages till the fall of the Roman empire, vol. 1, Murray, London, 1879.

[Burton 1875] R. F. Burton, Ultima Thule or a summer in Iceland, Nimmo, London, 1875. Both vol. 1 and vol. 2 are available online.

[Casson 1971] L. Casson, Ships and seamanship in the ancient world, Princeton University Press, 1971.

[Cornwall et al. 2013] C. Cornwall, A. Horiuchi, and C. Lehman, "NOAA ESRL solar position calculator", 2013, available at http://www.esrl.noaa.gov/gmd/grad/solcalc/azel.html.

[Dicks 1960] D. R. Dicks, The geographical fragments of Hipparchus, University of London Classical Studies 1, Athlone, London, 1960.

[Dilke 1985] O. A. W. Dilke, Greek and Roman maps, Thames and Hudson, London, 1985.

[Diller 1934] A. Diller, "Geographical latitudes in Eratosthenes, Hipparchus and Posidonius", Klio 27 (1934), 258-269.

[Gosselin 1798] P. F. J. Gosselin, Recherches sur la géographie systématique et positive des anciens, l'Imprimerie de la République, Paris, 1798.

[Helle 2008] K. Helle, "Introduction", pp. 1-12 in Cambridge history of Scandinavia, edited by K. Helle, Cambridge University Press, 2008.

[Hennig 1944] R. Hennig, Terrae incognitae, vol. 1, 2nd ed., Brill, Leiden, 1944.

[Honigmann 1929] E. Honigmann, Die sieben Klimata und die Poleis Episemoi: eine Untersuchung zur Geschichte der Geographie und Astrologie im Altertum und Mittelalter, Winter's Universitätsbuchhandlung, Heidelberg, 1929.

[Johansen and Vorren 1986] O. S. Johansen and K.-D. Vorren, "The prehistoric expansion of farming into 'Arctic' Norway: a chronology based on ${ }^{14}$ C dating”, Radiocarb. 28:2A (1986), 739-747.

[Johnson 1994] D. S. Johnson, Phantom islands of the Atlantic, Goose Lane, Fredericton, NB, 1994.

[Jones 1917-1932] H. L. Jones (editor), The geography of Strabo, Loeb Classical Library, Heinemann, London, 1917-1932.

[Jones 2002] A. Jones, "Eratosthenes, Hipparchus, and the obliquity of the ecliptic", J. Hist. Astron. 33:1 (2002), 15-19.

[Jones 2011] A. Jones, "Supplementary notes", pp. 455-476 in A survey of the Almagest, edited by A. Jones, Springer, New York, 2011.

[Manitius 1894] K. Manitius (editor), Hipparchi in Arati et Eudoxi Phaenomena commentariorum libri tres, B. G. Teubner, Leipzig, 1894.

[Manitius 1898] K. Manitius (editor), Gemini Elementa astronomiae, B. G. Teubner, Leipzig, 1898. 
[Manitius 1912] K. Manitius (editor), Des Claudius Ptolemäus Handbuch der Astronomie, B. G. Teubner, Leipzig, 1912.

[Marx 2013] C. Marx, "On resistant $L_{p}$-norm estimation by means of iteratively reweighted least squares”, J. Appl. Geod. 7:1 (2013), 1-10.

[Marx 2014] C. Marx, "Rectification of position data of Scotland in Ptolemy's Geographike Hyphegesis”, Surv. Rev. 46:337 (2014), 231-244.

[Marx and Kleineberg 2012] C. Marx and A. Kleineberg, Die Geographie des Ptolemaios: Geographike Hyphegesis Buch 3: Europa zwischen Newa, Don und Mittelmeer, Epubli, Berlin, 2012.

[Meeus 1991] J. Meeus, Astronomical algorithms, Willmann-Bell, Richmond, VA, 1991.

[Nansen 1911] F. Nansen, Nebelheim: Entdeckung und Erforschung der nördlichen Länder und Meere, Band I, Brockhaus, Leipzig, 1911. Reprinted by Adamant, Chestnut Hill, MA, 2005.

[Neugebauer 1975] O. Neugebauer, A history of ancient mathematical astronomy, Studies in the History of Mathematics and Physical Sciences 1, Springer, Berlin, 1975.

[Radt 2002-2011] S. Radt (editor), Strabons Geographika, Vandenhoeck \& Ruprecht, Göttingen, 2002-2011.

[Rawlins 1985] D. Rawlins, "Ancient geodesy: achievement and corruption", Vistas Astron. 28:1 (1985), 255-268.

[Rawlins 2009] D. Rawlins, "Aubrey Diller, Hipparchos, \& sph trig's history”, DIO 16 (2009), 1838.

[Rivet and Smith 1979] A. L. F. Rivet and C. Smith, The place-names of Roman Britain, Princeton University Press, 1979.

[Roller 2010] D. W. Roller, Eratosthenes' geography, Princeton University Press, 2010.

[Russo 2013] L. Russo, "Ptolemy's longitudes and Eratosthenes' measurement of the earth's circumference”, Math. Mech. Complex Syst. 1:1 (2013), 67-79.

[Shcheglov 2007] D. Shcheglov, "Hipparchus' table of climata and Ptolemy's geography", Orb. Terr. 9 (2007).

[Sporrong 2008] U. Sporrong, "The Scandinavian landscape and its resources", pp. 15-42 in Cambridge history of Scandinavia, 1: Prehistory to 1520, edited by K. Helle, Cambridge University Press, 2008.

[Strous 2012] L. Strous, “Astronomy answers: position of the sun”, 2012, available at http://aa.quae.nl/ en/reken/zonpositie.html.

[Toomer 1974] G. J. Toomer, "The chord table of Hipparchus and the early history of Greek trigonometry", Centaurus 18:1 (1974), 6-28.

[Toomer 1984] G. Toomer (editor), Ptolemy's Almagest, Springer, New York, 1984. Revised reprint Princeton University Press, 1998.

[Vinje and Kvambekk 1991] T. Vinje and Å. S. Kvambekk, "Barents Sea drift ice characteristics", Polar Res. 10:special issue 1 (1991), 59-68.

[Whitaker 1982] I. Whitaker, “The problem of Pytheas' Thule”, Class. J. 77:2 (1982), 148-164.

Received 25 Jan 2014. Revised 15 Dec 2014. Accepted 30 Jan 2015.

CHRISTIAN MARX: ch.marx@gmx.net

Gropiusstraße 6, D-13357 Berlin, Germany 
EDITORIAL BOARD

ANTONIO CARCATERRA

ERIC A. CARLEN

FRANCESCO DELL'ISOLA

RAFFAELE ESPOSITO

ALBERT FANNJIANG

Gilles A. FranCFORT

Pierangelo MARCATI

JEAN-JACQUES MARIGO

PETER A. MARKOWICH

MARTIN OSTOJA-STARZEWSKI

PIERRE SEPPECHER

DAVID J. STEIGMANN

PAUl STEINMANN

PierRe M. SuQueT

MANAGING EDITORS

MICOL AMAR

CORRADO LATTANZIO

ANGELA MADEO

MARTIN OSTOJA-STARZEWSKI

ADVISORY BOARD

ADNAN AKAY

Holm AltenBaCH

MICOL AMAR

HARM ASKES

TEODOR ATANACKOVIĆ

VICTOR BERDICHEVSKY

GUY BOUCHITTÉ

ANDREA BRAIDES

ROBERTO CAMASSA

MAURO CARFORE

ERIC DARVE

FELIX DARVE

ANNA DE MASI

GianPiEtro DEL Piero

EMMANUELE Di BENEDETTO

BERNOLD FIEDLER

IRENE M. GAMBA

DAVID Y. GAO

SERGEY GAVRILYUK

TIMOTHY J. HEALEY

DOMINIQUE JEULIN

ROGER E. KHAYAT

CORRADO LATTANZIO

ROBERT P. LIPTON

ANGELO LUONGO

ANGELA MADEO

JUAN J. MANFREDI

CARLO MARCHIORO

GÉRARD A. MAUGIN

ROBERTO NATALINI PATRIZIO NEFF

ANDREY PIATNITSKI

ERRICO PRESUTTI

MARIO PULVIRENTI

LUCIO RUSSO

Miguel A. F. SANJUAN

PATRICK SElVADURAI

ALEXANDER P. SEYRANIAN

MIROSLAV ŠILHAVÝ

GUIDO SWEERS

ANTOINETTE TORDESILLAS

LEV TRUSKINOVSKY

JUAN J. L. VELÁZQUEZ VINCENZO VESPRI ANGELO VULPIANI msp.org/memocs

Università di Roma "La Sapienza", Italia

Rutgers University, USA

(CO-CHAIR) Università di Roma "La Sapienza", Italia

(TREASURER) Università dell'Aquila, Italia

University of California at Davis, USA

(CO-CHAIR) Université Paris-Nord, France

Università dell'Aquila, Italy

École Polytechnique, France

DAMTP Cambridge, UK, and University of Vienna, Austria

(CHAIR MANAGING EDITOR) Univ. of Illinois at Urbana-Champaign, USA

Université du Sud Toulon-Var, France

University of California at Berkeley, USA

Universität Erlangen-Nürnberg, Germany

LMA CNRS Marseille, France

Università di Roma "La Sapienza", Italia

Università dell'Aquila, Italy

Université de Lyon-INSA (Institut National des Sciences Appliquées), France

(CHAIR MANAGING EDITOR) Univ. of Illinois at Urbana-Champaign, USA

Carnegie Mellon University, USA, and Bilkent University, Turkey

Otto-von-Guericke-Universität Magdeburg, Germany

Università di Roma "La Sapienza", Italia

University of Sheffield, UK

University of Novi Sad, Serbia

Wayne State University, USA

Université du Sud Toulon-Var, France

Università di Roma Tor Vergata, Italia

University of North Carolina at Chapel Hill, USA

Università di Pavia, Italia

Stanford University, USA

Institut Polytechnique de Grenoble, France

Università dell'Aquila, Italia

Università di Ferrara and International Research Center MEMOCS, Italia

Vanderbilt University, USA

Freie Universität Berlin, Germany

University of Texas at Austin, USA

Federation University and Australian National University, Australia

Université Aix-Marseille, France

Cornell University, USA

École des Mines, France

University of Western Ontario, Canada

Università dell' Aquila, Italy

Louisiana State University, USA

Università dell'Aquila, Italia

Université de Lyon-INSA (Institut National des Sciences Appliquées), France University of Pittsburgh, USA

Università di Roma "La Sapienza”, Italia

Université Paris VI, France

Istituto per le Applicazioni del Calcolo "M. Picone", Italy

Universität Duisburg-Essen, Germany

Narvik University College, Norway, Russia

Università di Roma Tor Vergata, Italy

Università di Roma "La Sapienza”, Italia

Università di Roma “Tor Vergata”, Italia

Universidad Rey Juan Carlos, Madrid, Spain

McGill University, Canada

Moscow State Lomonosov University, Russia

Academy of Sciences of the Czech Republic

Universität zu Köln, Germany

University of Melbourne, Australia

École Polytechnique, France

Bonn University, Germany

Università di Firenze, Italia

Università di Roma La Sapienza, Italia

MEMOCS (ISSN 2325-3444 electronic, 2326-7186 printed) is a journal of the International Research Center for the Mathematics and Mechanics of Complex Systems at the Università dell'Aquila, Italy.

Cover image: "Tangle” by $\odot$ John Horigan; produced using the Context Free program (contextfreeart.org).

PUBLISHED BY

7 mathematical sciences publishers

nonprofit scientific publishing

http://msp.org/

(C) 2015 Mathematical Sciences Publishers 
Mathematics and Mechanics of Complex Systems vol. 3 no. 4

An analysis of the latitudinal data of Eratosthenes and Hipparchus

\section{Christian Marx}

Spatial and material stress tensors in continuum mechanics 341 of growing solid bodies

Jean-François Ganghoffer

A crack with surface elasticity in finite plane elastostatics 365 $\mathrm{Xu}$ Wang and Peter Schiavone

An investigation of the active damping of suspension bridges

André Preumont, Matteo Voltan, Andrea Sangiovanni, Renaud Bastaits, Bilal Mokrani and David Alaluf

MEMOCS is a journal of the International Research Center for the Mathematics and Mechanics of Complex Systems at the Università dell' Aquila, Italy.

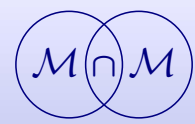

